UNIVERSIDADE FEDERAL FLUMINENSE

FACULDADE DE VETERINÁRIA

PROGRAMA DE PÓS-GRADUAÇÃO EM MEDICINA VETERINÁRIA

ÁREA DE CONCENTRAÇÃO EM HIGIENE VETERINÁRIA E

PROCESSAMENTO TECNOLÓGICO DE PRODUTOS DE ORIGEM ANIMAL

RAQUEL LIMA SALGADO

AVALIAÇÃo PARASITOLÓGICA DO PESCADO

FRESCO COMERCIALIZADO NO SUDESTE DO PARÁ

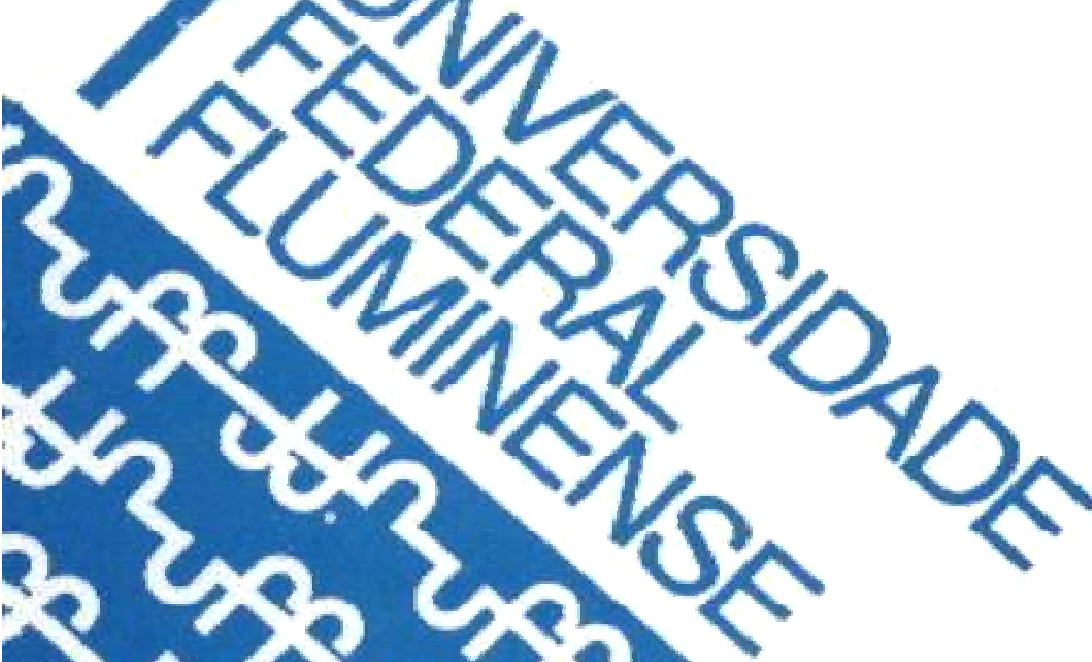

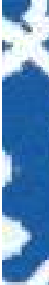


RAQUEL LIMA SALGADO

\title{
AVALIAÇÃO PARASITOLÓGICA DO PESCADO FRESCO COMERCIALIZADO NO SUDESTE DO PARÁ.
}

\author{
Tese apresentada ao Programa \\ de Pós-Graduação em Medicina \\ Veterinária da Universidade \\ Federal Fluminense, como \\ requisito parcial para obtenção do \\ Grau de Doutor. Área de \\ Concentração: Higiene Veterinária \\ e Processamento Tecnológico de \\ Produtos de Origem Animal.
}

Orientador: Prof. Dr. SÉRGIO CARMONA DE SÃO CLEMENTE

Niterói/RJ

2010 
RAQUEL LIMA SALGADO

\title{
AVALIAÇÃO PARASITOLÓGICA DO PESCADO FRESCO COMERCIALIZADO NO SUDESTE DO PARÁ.
}

\author{
Tese apresentada ao Programa \\ de Pós-Graduação em Medicina \\ Veterinária da Universidade \\ Federal Fluminense, como \\ requisito parcial para obtenção do \\ Grau de Doutor. Área de \\ Concentração: Higiene Veterinária \\ e Processamento Tecnológico de \\ Produtos de Origem Animal.
}

Aprovado em 23 / 06 / 2010

BANCA EXAMINADORA

Prof. Dr. Sérgio Carmona de São Clemente

Universidade Federal Fluminense

Prof. Dr. Francisco Carlos de Lima

Universidade Federal Fluminense

Prof. Dr. Luciano Antunes Barros

Universidade Federal Fluminense

Prof. Dr. Marcelo Knoff

Fundação Oswaldo Cruz

Prof. Dr. Edivaldo Sampaio de Almeida Filho

Universidade Federal do Mato Grosso

Niterói/RJ

2010 


\section{AGRADECIMENTOS}

Aos meus pais, Sueli Teresinha Lima, Jorge Garrido Salgado e Neiva Ivone de Souza Salgado por me apoiarem e incentivarem, por perdoarem os meus momentos de ausência, e por não pouparem sacrifícios para o meu sucesso. Amo vocês!

À minha avozinha Glória dos Santos Lima por ter sido fundamental na minha criação, por sua imensa dedicação e carinho, não medindo esforços para me fazer feliz.

Ao meu noivo Josemir de Souza Gonçalves pela paciência, apoio, carinho, e por me fazer acreditar que eu era capaz. Era inevitável me apaixonar por você. Somos ao mesmo tempo tão parecidos e tão diferentes que a cada dia da nossa convivência aprendo a te amar ainda mais e a me conhecer melhor. Te amo meu melhor amigo e meu futuro marido. Obrigada por me fazer querer ser uma pessoa melhor.

Aos amigos Drausio Ferreira, Bruno Carvalho, Patrícia Millar Goulart e Fernanda Lima, por estarem sempre comigo e apoiarem em todos os momentos que precisei, aturando o meu mau humor, e ainda assim serem meus melhores amigos. Sem vocês nada disso seria possível.

Às minhas eternas amigas Patrícia Navarro e Mariana Martins por estarem presentes em todas as etapas da minha vida, acompanhando meus erros e acertos e me guiando no caminho do sucesso.

Ao Professor Dr. Rogério Tortelly pela sua eterna amizade, apoio e incentivo, e por ter sempre acreditado em mim. Espero ainda te dar muito orgulho.

Ao professor e amigo, Dr. Francisco Carlos de Lima, pela confiança desde o primeiro contato, pela dedicação, carinho e atenção.

Ao meu Orientador Prof. Dr. Sérgio Carmona de São Clemente, pela oportunidade, confiança, orientação e atenção que foram fundamentais em todos os momentos.

À Coordenação da Pós-graduação em Hig. Vet. Proc. Tec. P.O.A. na pessoa da Profa. Dra. Mônica Queiroz, por compreender meus momentos de incerteza, aceitar meus instantes de ausência, permitindo assim que eu alcançasse meu maior objetivo, a efetivação como professora universitária.

Em especial aos alunos do Curso de Graduação em Zootecnia da Universidade Federal Rural da Amazônia - Campus de Parauapebas, integrantes do projeto de parasitologia do pescado Irislene Santos Paiva, Bruna Menino Costa, Janaína Barros Luz, Márcia dos Santos Carvalho, Clarisse da Silva Aguiar, Aldean de Lima Nascimento, Márjara Alyne Mulato Sampaio e Wildiney Freire de Oliveira, pelo apoio fundamental no desenvolvimento desta tese.

À CAPES (Fundação Coordenação de Aperfeiçoamento de Pessoal de Nível Superior) pelo apoio financeiro. 


\section{SUMÁRIO}

RESUMO, p.07

ABSTRACT, p.08

1 INTRODUÇÃO, p.09

2 REVISÃO DE LITERATURA, p.13

2.1 IMPORTÂNCIA SÓCIO-ECONÔMICA DO PESCADO PARA O SUDESTE PARAENSE, p.13

2.2 PRINCIPAIS ESPÉCIES PESQUEIRAS COMERCIALIZADAS NO SUDESTE DO PARÁ, p. 16

2.2.1 Tambaqui (Colossoma macropomum), p.16

2.2.2 Tucunaré (Cichla spp.), p.18

2.2.3 Pescada branca (Cynoscion leiarchus), p.19

2.2.4 Dourada (Brachyplatystoma rousseauxii), p.20

2.3 ENDOPARASITOS DE PEIXE DE IMPORTÂNCIA HIGIÊNICO-SANITÁRIA, p.21

2.3.1 Nematóides, p.22

2.3.1.1 Anisakis spp., p.25

2.3.1.2 Contracaecum spp., p.26

2.3.1.3 Pseudoterranova spp., p.27

2.3.2 Cestóides, p.27

2.3.3 Trematódeos, p.31

2.4 MEDIDAS DE CONTROLE E PREVENÇÃO DE ZOONOSES PARASITÁRIA, p.32 


\section{ARTIGOS CIENTÍFICOS, p.36}

3.1 Helmintos de importância higiênico-sanitária em douradas (Brachyplatystoma rousseauxii) capturadas no litoral norte do Brasil. (ACTA AMAZÔNICA), p.37

3.2 Pesquisa de helmintos com potencial zoonótico em tambaquis (Colossoma macropomum) e tucunarés (Cichla spp.) comercializados no sudeste do Pará. (REVISTA BRASILEIRA DE CIÊNCIA VETERINÁRIA), p.53

3.3 Larvas de helmintos de importância higiênico-sanitária em pescada branca (Cynoscion leiarchus) comercializada no sudeste paraense (REVISTA BRASILEIRA DE PARASITOLOGIA VETERINÁRIA), p.67

4 CONSIDERAÇÕES FINAIS, p.74

5 REFERÊNCIAS BIBLIOGRÁFICAS, p.75 


\section{RESUMO}

Os peixes são elementos fundamentais e insubstituíveis da dieta humana. No Brasil, a região Norte é a principal produtora de pescado, com destaque para o Estado do Pará que é o maior produtor brasileiro na pesca continental e tem na piscicultura a sua atividade aquícola mais importante, com uma diversidade de produtores desde o cultivo de subsistência à produção voltada para o comércio exterior. Apesar de sua importância para a saúde e economia local, o pescado comercializado no sudeste paraense ainda é pouco estudado quanto a sua fauna parasitológica de importância higiênico-sanitária. Neste contexto, o presente trabalho teve como o objetivo avaliar a diversidade da fauna parasitária de interesse em saúde pública de quatro das principais espécies pesqueiras do Sudeste do Pará: tambaqui, Colossoma macropomum; tucunaré, Cichla spp.; dourada, Brachyplatystoma rousseauxii; e pescada branca, Cynoscion leiarchus. Durante os meses de janeiro a dezembro de 2009, foram analisados 40 exemplares de cada espécie, adquiridos em feiras-livres do município de Parauapebas - PA/Brasil, totalizando 160 espécimes. Os peixes tiveram sua serosa abdominal e musculatura inspecionados quanto a presença de parasitos. Foram avaliadas a prevalência (P\%), intensidade de infecção (I), intensidade média de infecção (IM) e abundância média (AM) dos parasitos encontrados. Nos 40 espécimes de tambaquis, Colossoma macropomum, analisados não foi registrada a presença de parasitismo. Dois gêneros de alto potencial zoonótico foram identificados em 11 exemplares de tucunaré, Cichla spp. Sete espécimes encontravam-se parasitados por Contracaecum spp. (P\% 17,5; IM 1,7; AM 0,275) e cinco por Clinostomum complanatum (P\% 12,5; IM 2,5; AM 0,92). Dois dos 11 exemplares encontravam-se parasitados por ambos os gêneros. Dos 40 espécimes de dourada, Brachyplatystoma rousseauxii, analisados, seis encontravam-se parasitados por Anisakis spp. $(P \%=15 ; \mathrm{IM}=12 ; \mathrm{AM}=1,8)$, um por Poecilancistrium caryophyllum ( $\mathrm{P} \%=2,5 ; \mathrm{I}=1 ; \mathrm{A}=0,02)$ e um por Pterobothrium heteracanthum $(\mathrm{P} \%=2,5 ; \mathrm{I}=1 ; \mathrm{A}=0,02)$. Foram identificadas duas diferentes espécies de parasitos em 15 dos 40 espécimes de pescada branca, Cynoscion leiarchus, analisados. Nematóides do gênero Anisakis spp. foram observados parasitando 15 exemplares $(\mathrm{P} \%=37,5 \%)$, com I variando entre três e 42 parasitos por peixe; IM de 18,06; e AM de 6,77. Três exemplares apresentaram parasitismo múltiplo, por Anisakis spp. e Poecilancistrium caryophyllum ( $\mathrm{P} \%=7,5 \%$ ), com intensidade de infecção variando entre um e dois parasitos por peixe; intensidade média de infecção de 1,3; e abundância média de 0,1. A alta prevalência de parasitos com potencial zoonótico e aspecto repugnante em peixes frescos comercializados nas feiras nos municípios sudeste do Pará representa um grave risco à saúde humana e à economia local. Campanhas de educação sanitária e a capacitação dos fiscais sanitários municipais podem minimizar esse risco. Maiores estudos devem ser realizados com o pescado comercializado no sudeste do Pará.

PALAVRAS CHAVE: Amazônia, Anisakidae, Pará, helmintos, Brachyplatystoma rousseauxii, Cynoscion leiarchus, Cichla spp., Colossoma macropomum, Trypanorhyncha. 


\begin{abstract}
Fish as food are crucial and irreplaceable for human diet. In Brazil, the North is the main producer of fish, especially the state of Pará. This is the major producer in inland fisheries and fish farming has on its most important aquaculture activity with a variety of producers from subsistence farming to production-oriented for foreign trade. Despite its importance to health and local economy, the fish sold in the southeast of Pará has been few studied for their parasitological fauna of the hygienic and sanitary importance. In this context, this study aimed to evaluate the diversity of the parasite fauna of interest to public health of four major species fisheries in Southeast Pará: tambaqui tambaqui, Colossoma macropomum; tucunaré, Cichla spp., dourada, Brachyplatystoma rousseauxii; and pescada branca, Cynoscion leiarchus. During the months from January to December 2009, were analyzed 40 specimens of each species purchased in open-air markets in the city of Parauapebas - PA / Brazil, totaling 160 specimens. The fish had their serosa and abdominal musculature inspected for the presence of parasites. We evaluated the prevalence $(\mathrm{P} \%)$, infection intensity (I), mean intensity of infection (IM) and mean abundance (MA) of parasites. In the 40 specimens of tambaqui, analyzed was not recorded the presence of parasitism. Two kinds of high zoonotic potential were identified in 11 specimens of tucunaré. Seven specimens were parasitized by Contracaecum spp. ( $P$ $17.5 \%, \mathrm{Ml} 1.7,0.275 \mathrm{PM}$ ) and five Clinostomum complanatum ( $\mathrm{P} 12.5 \%, \mathrm{MI} 2.5,0.92$ AM). Two of 11 specimens were parasitized by both genders. Of the 40 specimens of dourada, analyzed, six were parasitized by Anisakis spp. $(P=15 \%, I M=12, A M=$ 1.8), one per Poecilancistrium caryophyllum $(P=2.5 \%, I=1, A=0.02)$ and one by Pterobothrium heteracanthum ( $\mathrm{P} \%=2,5, \mathrm{I}=1, \mathrm{~A}=0.02)$. We identified two different species of parasites in 15 of 40 specimens of pescada branca, analyzed. Nematodes of Anisakis spp. were observed parasitizing 15 specimens ( $\mathrm{P} \%=37.5 \%)$, with I varying between 3:42 parasites per fish, MI, 18.06, and 6.77 AM. Three specimens showed multiple parasitism by Anisakis spp. and Poecilancistrium caryophyllum (P\% $=7.5 \%$ ), with intensity of infection ranged between one and two per fish parasites; mean infection intensity of 1.3 , and average abundance of 0.1 . The high prevalence of parasites with zoonotic potential and look disgusting in fresh fish sold at fairs in towns southeast of Pará is a serious risk to human health and the local economy. Health education campaigns and training of municipal fiscal health can minimize this risk. Further studies must be conducted with the fish sold in the southeast of Pará.
\end{abstract}

KEY WORDS: Amazonia, Anisakidae, Pará, helminths, Brachyplatystoma rousseauxii Cynoscion leiarchus, Cichla spp. Colossoma macropomum, Trypanorhyncha. 


\section{INTRODUÇÃo}

O Estado do Pará é o segundo maior estado brasileiro, possuindo uma extensão territorial de $1.253 .165 \mathrm{~km}^{2}$, com $562 \mathrm{~km}$ de costa atlântica. A economia do Estado foi construída com ênfase na produção de culturas anuais e pecuária de corte extensiva desordenada, que traz riscos ao meio ambiente (GOVERNO DO ESTADO DO PARÁ, 2009).

A população do estado está estimada em 5.511 .000 habitantes (densidade de 4,3 habitantes por $\mathrm{km}^{2}$ ), divididos em 6 mesoregiões (Baixo Amazonas; Sudoeste Paraense; Marajó; Sudeste Paraense; Nordeste do Pará; Belém) (Figura 1) e microrregiões, que compõem 143 municípios, onde 53\% da população se concentra em áreas urbanas (SEPOF, 2009).

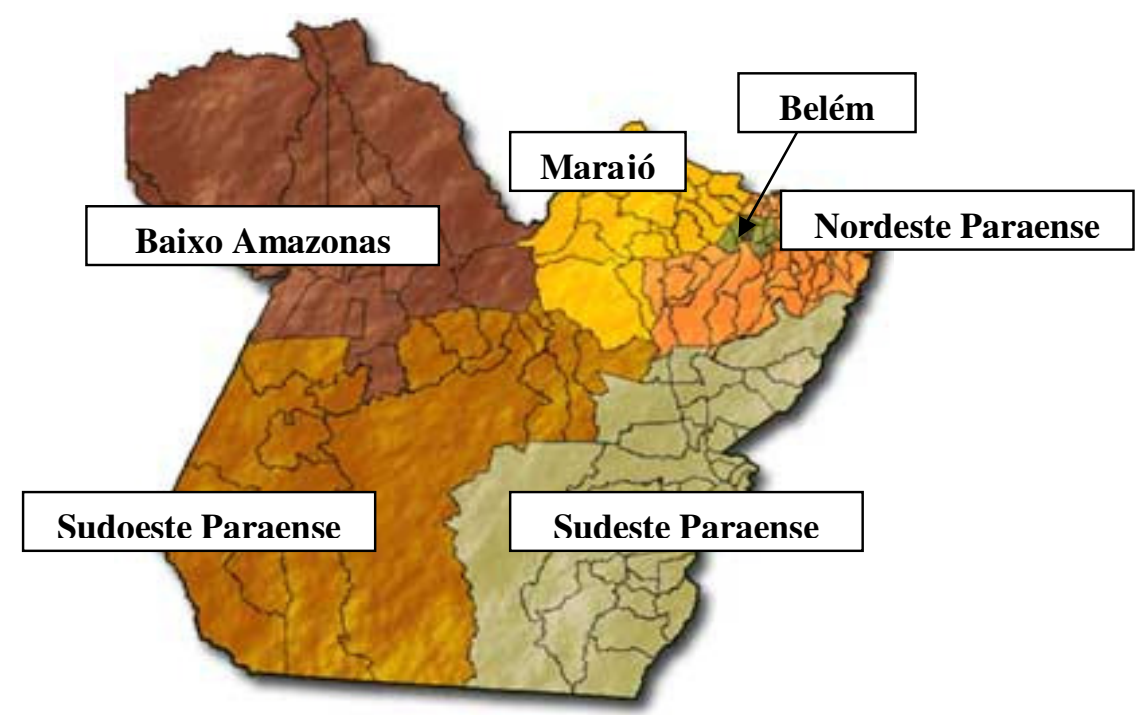

Fonte: SEPOF, 2009

Figura 1 - Mapa geográfico com as divisões das meso e microrregiões do Pará 
A mesorregião Sudeste do Pará é internacionalmente conhecida pelos conflitos de terras travados entre garimpeiros, membros do Movimento dos Sem Terra (MST), povos indígenas e a população local. O município de Parauapebas é o segundo em extensão territorial da região, e abriga o maior número de assentamentos e invasões de terra, sendo 44 mil hectares (ha) de área assentada, onde vivem cerca de 520 famílias, que têm na produção de lavoura branca (mandioca, feijão, milho, arroz) produção animal extensiva e na aquicultura e pesca, suas principais formas de sustento (SEPOF, 2009).

A aquicultura é uma das atividades zootécnicas que vêm se destacando como alternativa econômica para o pequeno e médio produtor, sendo propícia ao aproveitamento de áreas improdutivas, transformando-as e elevando sua potencialidade e produtividade.

No Estado do Pará, cerca de 600 ha de área hídrica estão sendo utilizados na implantação de projetos para a criação de peixes. A produção estimada da aquicultura de água doce paraense foi de 2.245 toneladas em 2007, sendo deste total 2.240 toneladas de peixes, destacando-se o tambaqui (Colossoma macropomum) e a tilápia-do-nilo (Oreochromis niloticus) (IBAMA, 2007).

Já a pesca extrativista na região amazônica é favorecida pela matéria orgânica oriunda da decomposição das florestas de mangue e das planícies inundadas do rio Amazonas. Desta forma carreando sedimentos para a plataforma continental, criando condições propícias para o crescimento e desenvolvimento de diversas espécies de peixes (NAHUM, 2006), que em muitos casos constituem a principal forma de sustento da população riberinha.

O pescado é de extrema importância na dieta alimentar por sua riqueza em nutrientes com elevado teor protéico e de aminoácidos essenciais, execelente perfil lipídico rico em ácidos graxos insaturados, aliado ao baixo teor de colesterol.

Desde a origem da humanidade, os peixes e animais aquáticos, têm grande importância na alimentação. A participação dos produtos da pesca na alimentação é muito variável, onde em regiões distantes do litoral o consumo do pescado representa, em média, de $12 \%$ da proteína animal ingerida, enquanto nas zonas costeiras, esta percentagem pode alcançar 70\% (VÁZQUEZ-LÓPEZ et al., 2001).

No entanto, grande parte dos pescadores, piscicultores e comerciantes brasileiros desconhece a existência dos parasitos e a importância do controle 
zoossanitário para a profilaxia das doenças, além de desconhecer as perdas econômicas que estes podem acarretar.

Os peixes de origem marinha ou de água doce apresentam uma vasta fauna parasitária, com destaque para os nematóides da família Anisakidae, cujas larvas, quando ingeridas pelo homem, podem determinar lesões em diferentes pontos do trato gastrointestinal e também reações alérgicas. Cestóides da ordem trypanorhyncha, apesar de não possuírem potencial zoonótico, devido ao aspecto repugnante que promovem ao pescado, resultam em condenações pela fiscalização sanitária e rejeição pelo público consumidor, acarretando em grandes perdas econômicas para o setor pesqueiro.

As zoonoses parasitárias transmitidas por pescados vêm merecendo destaque no mundo por serem incriminadas em surtos de enfermidades transmitidas por alimentos associados ao consumo de pescado crú ou insuficientemente cozido (GERMANO e GERMANO, 1998; OKUMURA et al., 1999; PEREIRA et al., 2000; OKUMURA et al., 2001; LUQUE, 2004; OLIVEIRA e VIEGAS, 2004). Em 1995, estudos da Organização Mundial de Saúde (OMS) estimaram que 39 milhões de pessoas em todo o mundo haviam contraído algum tipo de parasitose transmitida pela ingestão de peixes ou crustáceos crus ou mal cozidos (FAO, 2001).

Apesar da grande importância para a saúde e economia local, o levantamento da fauna parasitária de importância higiênico-sanitária do pescado comercializado no sudeste paraense ainda é pouco estudado.

Neste contexto, o presente trabalho teve como o objetivo avaliar a diversidade da fauna parasitária de interesse comercial e em saúde pública das principais espécies de peixes comercializadas no sudeste do Pará, e determinar a prevalência, intensidade de infecção, intensidade média de infecção e abundância média dos parasitos encontrados. 


\section{REVISÃO DE LITERATURA}

\subsection{IMPORTÂNCIA SÓCIO-ECONÔMICA DO PESCADO PARA O SUDESTE PARAENSE}

A demanda pelo pescado vem aumentando nos últimos anos, impulsionada principalmente pelo crescimento da população e pela tendência mundial em busca de alimentos saudáveis. Uma nova postura do mercado consumidor está sendo construída como resultado da preocupação com a saúde e motivada pela consciência de preservação ambiental amplamente divulgada pela mídia.

A pesca e a aquicultura, nos últimos anos, obtiveram os maiores índices de produtividade, abastecendo o mercado mundial com cerca de 140 milhões de toneladas de peixes, ou $16,6 \mathrm{~kg}$ per capita/ano. Pelo ritmo de crescimento populacional mundial, estima-se, para o ano de 2025, uma população em torno de 8,5 bilhões de pessoas, que apresentarão uma demanda por peixes na ordem de 162 milhões de toneladas. Sem o aumento das capturas, que estão estagnadas em aproximadamente 95 milhões de toneladas/ano há mais de 20 anos, a aquicultura terá que suprir este déficit respondendo por 77 milhões de toneladas, o que representaria um aumento de $600 \%$ em 35 anos (FAO, 2006).

Segundo dados da FAO - Food and Agriculture Organization of United Nations (2006), a producão aquícola mundial aumentou vertiginosamente nos últimos 50 anos. De uma produção de menos de um milhão de toneladas no começo da década de 50 até 51,7 milhões de toneladas em 2006. Nos últimos dez anos este aumento foi ainda mais acentuado, onde a aquicultura foi responsável por 
aproximadamente $43 \%$ da produção mundial, enquanto nos anos 80 , esse número era apenas de $9 \%$.

O Brasil apresenta um grande potencial para 0 desenvolvimento da aquicultura. Formado por $8.400 \mathrm{~km}$ de costa marítima e 5.500 .000 hectares em reservatórios de águas doces, o país comporta aproximadamente $12 \%$ da água doce disponível no planeta (SEAP, 2008). A disponibilidade de recursos hídricos, o clima extremamente favorável, a mão-de-obra abundante e a crescente demanda por pescado no mercado interno têm contribuído para aumentar a produtividade nacional.

O Brasil já ocupa posição de destaque na produção de algumas espécies da aquicultura mundial. Dentre os países latino-americanos, o Brasil foi o segundo maior produtor de pescado cultivado em 2005, atrás somente do Chile. Foi o maior produtor de tilápias, à frente de Honduras e Colômbia, ambos com cerca de 28 mil toneladas, e do Equador, com 22 mil toneladas e o segundo maior produtor de camarão marinho, atrás apenas do México, que produziu 72 mil toneladas no mesmo ano (KUBITZA, 2007). Na última década, a aquicultura brasileira cresceu em média $23,8 \%$ ao ano, enquanto a aquicultura mundial apenas 10,2\% (FAO, 2006).

Alguns setores, como o da carcinicultura marinha e o da ostreicultura, chegaram a ampliar suas produções em mais de 50\% de 2000 para 2001 (SEAP, 2008). Entre 2000 e 2005 a produção nacional de tilápias dobrou, e a de camarão marinho praticamente triplicou. A tilápia, o camarão marinho, os caracídeos (em particular os peixes redondos) e as carpas somaram $87 \%$ da produção da aquicultura nacional em 2005 (KUBITZA, 2007).

A região Norte é a segunda maior produtora de pescado do Brasil, com uma produção anual estimada em cerca de 250 mil toneladas, ficando atrás somente da região Nordeste com uma produção anual de 322 mil toneladas. Boa parte desta produção é proveniente da piscicultura (IBAMA, 2007).

A piscicultura na região Amazônica está em constante ascensão, motivada pela diminuição dos estoques pesqueiros e como forma de sustento para populações de baixa renda. As espécies mais cultivadas da bacia Amazônica são o tambaqui (Colossoma macropomum), o pirarucu (Arapaima gigas) e o curimatâ (Prochilodus sp.). Entre as exóticas destaca-se a tilápia (Orechromis spp.) (IBAMA, 2007). 
O Estado do Pará possui $98.292 \mathrm{~km}^{2}$ de água interiores, o que corresponde a $38 \%$ da água doce do Brasil. Atualmente é o terceiro produtor nacional de pescado, responsável por quase $50 \%$ da produção de toda a região Norte. Os seus $21 \mathrm{mil} \mathrm{km}$ de rios, $74.780 \mathrm{~km}$ de igarapés e várzeas e $562 \mathrm{~km}$ de costa atlântica, entre o Cabo Norte e a foz do rio Gurupi, onde a atividade pesqueira (artesanal e industrial) se desenvolve, favorecem amplamente a aquicultura (SEMPROR, 2009).

Atualmente a piscicultura é a atividade aquícola mais importante do estado, com cerca de 600 hectares de área hídrica utilizados na implantação de projetos para a criação de peixes. Distribuída em praticamente todos os municípios, exibe uma diversidade de produtores desde o cultivo estritamente de subsistência ao grande produtor voltado à exportação. Mas o predomínio ainda é de propriedades com menos de 2 ha de lamina de água, com mais de $90 \%$ dos produtores nesta situação. Esta vasta maioria formada por pequenos produtores é caracterizada também por ser uma atividade de subsistência, onde mesmo os que produzem com fins comerciais a praticam de forma rudimentar (GAMA, 2008).

Diversos programas de incentivo à piscicultura vêm sendo criados nos municípios do interior do estado. Em Parauapebas já estão sendo desenvolvidos projetos de piscicultura com o objetivo de promover a criação de peixes como alternativa real e rentável em substituição à pecuária. O programa é visto como uma alternativa ecologicamente viável, já que um hectare cultivado com peixes produz mais do que com qualquer outra espécie animal. Dentre as espécies mais cultivadas está o tambaqui (SEMPROR, 2009).

Além da aquicultura, a pesca extrativista marinha e continental são responsáveis por boa parte da produção nacional de pescado.

No Brasil a pesca extrativista marinha, com uma produção aproximada de $539.966,5$ toneladas, representou $50,4 \%$ da produção total de pescado em 2007, sendo o estado do Pará o maior representante da região Norte $(90,9 \%)$ (IBAMA, 2007).

A pesca extrativista continental se constitui na principal fonte de renda dos moradores de zonas ribeirinhas. Estudos demonstram que a taxa de consumo de pescado na região Amazônica é a maior do mundo, com média estimada em 369 g/ pessoa/dia ou $135 \mathrm{~kg} /$ pessoa/ano, chegando a cerca de $600 \mathrm{~g} /$ pessoa/dia ou $219 \mathrm{~kg} /$ pessoa/ano em certas áreas do Baixo Rio Solimões e Alto Amazonas, muito acima dos $16,6 \mathrm{~kg}$ per capita/ano consumidos pela maioria da população mundial 
(CERDEIRA et al, 1997; BATISTA et al., 2004). Prevalece nessas regiões a pesca em pequena escala, onde grande parte do pescado capturado serve para consumo próprio ou é vendido em circunstâncias informais. O peixe de origem continental oferece, na maioria das vezes, a única fonte de proteína de qualidade acessível para a população de baixa renda e povos indígenas (COPESCAL, 2005).

\title{
2.2 PRINCIPAIS ESPÉCIES PESQUEIRAS COMERCIALIZADAS NO SUDESTE DO PARÁ
}

\subsubsection{Tambaqui - Colossoma macropomum}

\author{
Ordem Characiformes \\ Família Characidae \\ Subfamília Serrasalminae \\ Gênero Colossoma \\ Espécie Colossoma macropomum (Cuvier, 1816) \\ Nome popular: tambaqui, pacu vermelho
}

Anatomicamente caracterizam-se por possuir corpo com formato romboidal, de coloração castanho na metade superior e preta na inferior, podendo apresentar variação de cores para tons mais claros, conforme o seu habitat. Possuem nadadeira adiposa curta com raios na extremidade; boca prognata pequena e forte com dentes molariformes e duas series de dentes no pré-maxilar. Os espécimes adultos chegam a atingir $90 \mathrm{~cm}$ de comprimento e pesar $30 \mathrm{~kg}$ (MENEZES e FIGUEIREDO, 1980).

São habitantes naturais da Bacia Amazônica, contudo realizam migrações reprodutivas, tróficas e de dispersão que chegam a centenas de quilômetros. Durante a época de cheia habitam a mata inundada, onde se alimentam de frutos ou sementes. Com a chegada da seca, os indivíduos jovens permanecem nos lagos de várzea onde se alimentam de zooplâncton, e os adultos migram para os rios de águas barrentas para desovar (FERREIRA, 2006).

O tambaqui é um dos peixes economicamente mais valiosos da região Amazônica, mas nos últimos anos vem sofrendo forte pressão de pesca nos seus estoques naturais. A participação do tambaqui na produção total de pescado passou 
de 10,8\% em 1994 para 6,3\% em 1997 (GRAEF, 1995). Considera-se que a pesca nativa do tambaqui tenha atingido níveis de sobrexploração, sendo atualmente uma espécie protegida pelo IBAMA, através da Portaria nำ08, de 02 de fevereiro de 1996 (IBAMA, 1996) que proíbe a captura e comercialização de indivíduos de pequeno porte e a pesca, comercialização, beneficiamento e armazenamento nos períodos de reprodução (de 1ำ de dezembro a 28 de fevereiro).

O tambaqui é uma das espécies que mais desperta interesse para a piscicultura no Brasil, por ser de fácil adaptação, apresentar um rápido crescimento, excelente conversão alimentar, tolerância à baixos níveis de oxigênio dissolvido na água e alta taxa de sobrevivência de alevinos (85\%) (MELO et al., 2001).

\subsubsection{Tucunaré - Cichla spp.}

Ordem Perciformes

Família Cichlidae

Subfamília Cichlinae

Gênero Cichla

Espécies Cichla ocellaris, Bloch e Schneider, 1801; Cichla monoculus, Spix e Agassiz, 1831.

Nome popular: tucunaré

Nativo das regiões das Bacias Amazônica e do Araguaia, mas introduzido nos reservatórios da bacia do Prata, em algumas áreas do Pantanal, no rio São Francisco e nos açudes do Nordeste, seu cultivo não é muito comum, sendo a pesca predatória a principal forma de obtenção desses espécimes. Caracterizam-se por serem sedentários (não realizam migrações), viverem em lagos, lagoas e na desembocadura e margens dos rios. Formam casais e se reproduzem em ambientes lênticos, onde constroem ninhos e cuidam da prole. Têm hábitos diurnos. Alimentamse principalmente de peixes e camarões. Por seu hábito de perseguição à presa, o torna o principal peixe esportivo da Amazônia e um dos principais objetivos da pesca esportiva no Brasil (AMBIENTE BRASIL, 2010).

Anatomicamente são peixes de corpo revestido por escamas, alongado e achatado laterolateralmente, e chegam a atingir até um metro de comprimento total. 
Existem ao menos 14 espécies de tucunarés na Amazônia, sendo cinco espécies mais prevalentes: Cichla ocellaris, C. temensis, C. monoculus, $C$. orinocensis e $C$. intermedia. $\mathrm{O}$ tamanho, a cor, a forma e a distribuição de manchas pelo corpo, são caracteres que variam de acordo com a espécie, servindo de parâmetros para identificação. No entanto todas apresentam um caracter morfológico diagnóstico representado por uma mancha em forma de ocelo no pedúnculo caudal (TEIXEIRA FILHO, 1991).

O Cichla ocellaris caracteriza-se por apresentar uma mancha escura longitudinal, contínua ou interrompida sob as nadadeiras peitorais, e três ou quatro faixas verticais escuras na região superior logo abaixo da nadadeira dorsal, nunca ultrapassando a linha mediana do corpo. O Cichla monoculus distingui-se das outras espécies por apresentar três faixas verticais escuras nas laterais do corpo que alcançam a região ventral, e pequenas manchas pretas atrás do olho formando uma faixa descontínua (SOUZA, et al., 2008).

\subsubsection{Pescada branca (Cynoscion leiarchus)}

Ordem Perciformes

Família Sciaenidae

Gênero Cynoscion

Espécie Cynoscion leiarchus (Cuvier, 1830)

Nome popular: pescada branca

$\mathrm{Na}$ costa brasileira existem mais de 30 espécies de pescada, dentre as mais comuns estão a pescada branca ( $C$. leiarchus) e a pescada-amarela ( $C$. acoupa). São peixes demersais e pelágicos, frequentam as águas rasas próximas às costas, baías e enseadas e locais pedregosos com corais. Formam cardumes nos poços e regiões profundas e se alimentam preferencialmente de crustáceos, como camarões, e de pequenos peixes.

A pescada branca (Cynoscion leiarchus) pode ser encontrada do Panamá ao sul do Brasil, sendo mais abundante na região norte do país. Habitam águas estuarinas, sob fundo de lama e areia, mas podem também ser encontradas no ambiente marinho. 
Anatomicamente caracterizam-se por possuir corpo prateado lateralmente $\mathrm{e}$ acizentado superiormente; nadadeira dorsal anterior escura, com dez espinhos e 20 a 24 raios; nadadeira caudal truncada e com a margem enegrecida; alcamçam 60 cm de comprimento e 2,0 a 2,5 kg (MENEZES e FIGUEIREDO, 1980).

\subsubsection{Dourada - Brachyplatystoma rousseauxii}

Ordem Siluriforme

Família Pimelodidae

Gênero Brachyplatystoma

Espécie Brachyplatystoma rousseauxii (Castelnau, 1855)

Nome popular: dourada

A dourada foi originalmente classificada em 1855 por Castelnau (1855) e taxonomicamente revisada em 1991 por Lundberg et al. (1991), quando teve sua nomeclatura científica modificada de Brachyplatystoma flavicans para Brachyplatystoma rousseauxii (FERREIRA, 1998).

Habitante comum das águas doces e de baixa salinidade da foz do Rio Amazonas, é encontrada com freqüência nos canais dos principais rios e afluentes de águas brancas do Amazonas, como os rios Madeira, Japurá, Solimões e Ucayli. (EIGEMANN e EIGENMANN, 1971; GOULDING, 1979, ZUANON, 1990; BARLETTA, 1995, SANYO, 1998).

A dourada, Brachyplatystoma rousseauxii, é um predador por excelência, atacando vorazmente os cardumes de peixes menores, principalmente peixes de escamas. Realiza longas migrações reprodutivas, percorrendo distâncias superiores a $4.000 \mathrm{~km}$, desde o estuário amazônico até a área pré-andina na Colômbia, Peru e Bolívia. Os peixes levam de dois a três anos para migrar rio acima, antes de desovar aos três anos de idade. As larvas são carreadas rio abaixo pela forte correnteza alcançando o estuário, próximo ao município de Belém, onde é o seu hábitat natural de crescimento. No estuário, alimentam-se de pequenos animais e permanecem na região até atingirem dois anos de idade. (BARTHEM e GOULDING, 1997).

Anatomicamente caracteriza-se por ser um peixe revestido de pele, com cabeça prateada e achatada, e corpo claro com reflexos dourados. Apresenta longos lobos na nadadeira caudal e barbilhões maxilares curtos. É uma espécie de grande 
porte, que pode chegar a mais de $1,5 \mathrm{~m}$ de comprimento total e pesar $20 \mathrm{~kg}$ (FERREIRA, 1998).

É uma das espécies de bagres de maior importância econômica para a pesca da região Norte, sendo capturada comercial e artesanalmente, sua exploração é feita por frotas pesqueiras de praticamente todas as vilas e cidades ao longo do rio Amazonas e seus principais tributários. (BARTHEM, 1992).

\subsection{PARASITOS DE PEIXE DE IMPORTÂNCIA HIGIÊNICO-SANITÁRIA}

Os peixes coexistem com parasitas e patógenos na natureza, em equilíbrio. Porém alterações ambientais como queda dos teores de oxigênio dissolvido (OD), aumento de gás carbônico $\left(\mathrm{CO}_{2}\right)$, amônia $\left(\mathrm{NH}_{3}\right)$ e nitrito $\left(\mathrm{NO}_{2}\right)$, altas estocagens e níveis de arraçoamento, remoção e reestocagem podem causar estresse, redução da resistência, ferimentos e facilitar 0 desenvolvimento de enfermidades (SNATURAL, 2009).

As alterações ambientais frequentemente estão associadas à interferência do homem. Na aquicultura, a intensificação dos cultivos faz com que se rompa o equilíbrio existente na relação parasito-hospedeiro-ambiente possibilitando o surgimento de enfermidades que levam à redução do crescimento e ganho de peso, diminuição da fertilidade e até mortalidades elevadas (CRESPO e CRESPO, 2003). A poluição ambiental, desmatamento e o aquecimento global influenciam diretamente na qualidade da água, alterando os teores de nutrientes, oxigênio e gás carbônicos dissolvidos.

Diversos são os grupos de parasitos que apresentam importância na produção e comercialização de peixes. Os endoparasitas (trematódeos, nematóides e cestóides) são apontados como agentes responsáveis por significativos prejuízos econômicos em peixes cultivados (KIM et al., 2002). Entretanto os prejuízos podem ser ainda maiores na comercialização e para saúde do consumidor, em função do aspecto repugnante ocasionado pela presença de cistos macroscópicos, de cestóides e trematódeos, na musculatura; e decorrente do potencial zoonótico que alguns parasitos apresentam. 


\subsubsection{Nematóides}

Dentre os parasitos com potencial zoonótico, os nematóides da família Anisakidae são os mais implicados em surtos de origem alimentar.

A família Anisakidae é considerada a maior dentro da superfamília Ascaridoidea, e inclui espécies que parasitam peixes, répteis, mamíferos e aves piscívoras (ANDERSON, 2000). Todos os representantes dessa família são dependentes do ambiente aquático para o desenvolvimento de seu ciclo biológico, que usualmente envolvem invertebrados e peixes como hospedeiros intermediários ou paratênicos. Os parasitas adultos habitam o trato digestivo de mamíferos marinhos, tendo seus ovos eliminados pelas fezes, e no ambiente aquático se desenvolvem até o estágio larvar. As larvas são ingeridas por peixes, crustáceos ou cefalópodes onde se desenvolvem até o terceiro estágio, quando então são ingeridas pelos mamíferos marinhos fechando o ciclo biológico (GIBSON, 1983; ANDERSON, 2000). Por vezes as larvas deslocam-se do tubo digestivo e se alojam em diferentes órgãos da cavidade celomática, ou invadem a musculatura formando pequenos espirais de dois a três milímetros de diâmetro (Figura 6), onde podem permanecer por mais de três anos ainda com capacidade infectante (SABATER e SABATER, 2006). O homem atua como hospedeiro acidental, adquirindo a larva através da ingestão de peixes crus ou mal cozidos, ligeiramente curado e/ou condimentado. Nele, o ciclo biológico do parasito não se completa (SMITH e WOOTTEN, 1978; VALLS et al., 2005).

A Família Anisakidae possui três gêneros principais parasitas de peixes: Anisakis sp., Pseudoterranova sp. e Contracaecum sp., aos quais são atribuídos os maiores números de casos registrados (HUSS, 1997; PEREIRA et al., 2000; MERCADO et al., 2001).

Os anisaquídeos foram reportados parasitando peixes e mamíferos marinhos por volta de 1700, mas somente em 1867, na Groelândia, foi relatado o primeiro caso de parasitismo em humanos (MYERS, 1976).

$\mathrm{Na}$ década de 60 a anisakiose ganhou destaque, quando diversos caso de parasitismo por Anisakis simplex em humanos foram descritos na Holanda. Desde então diversos casos têm sido relatados em todo o mundo. Os maiores índices são descritos em países de cultura oriental, onde é comum o hábito de consumir pescado cru. Somente no Japão foram relatados cerca de 1.000 casos de anisakiose 
em 1990 (DASCHNER et al, 1997).

A anisakiose humana foi classificada como uma antropozoonose de ampla distribuição geográfica, sendo mais frequente nos países em que o consumo de produtos de pesca ocorre sob forma de produtos crus, mal cozidos, defumados a frio, inadequadamente salgados e refrigerados (SÃO CLEMENTE, 1993b; OLIVEIRA e VIEGAS, 2004). São muitos os relatos da presença de larvas de terceiro e quarto estágio parasitando o homem, em países como o Japão (YOKOGAWA e YOSHIMURA, 1965; 1967; SUGIMACHI, 1978; SAKANARI, 1988), Estados Unidos (LITTLE e MACPHAIL, 1972; KATES et al., 1973; LITTLE e MOST, 1973; CHITWOOD, 1975; LICHTENFELS e BRANCATO, 1976; KLIKS, 1983), França (FABRESSE, 1984; HUBERT et al., 1989; PINEL, 1996), Itália (VALDISERRI, 1981; MAGGI, 2000), Espanha (VERA, 1991), Noruega (RUSHOVICH, 1983; JENSEN et al., 1994) e Chile (THIEL et al., 1960; KOBAYASHI et al., 1985; MERCADO et al., 1997). Embora no Brasil ainda não tenha sido descrito nenhum caso de anisakiose, com a popularização da culinária japonesa e o aumento no número de estabelecimentos de alimentos de origem oriental, esse risco é iminente.

Entende-se por anisakidose ou anisaquiose a infecção causada pela ingestão de larvas vivas de anisaquídeos. Estas podem se fixar na mucosa dos órgãos, determinando lesões em diferentes pontos do trato gastrointestinal, ou ainda migrar para localizações extragastrintestinais. A manifestação clínica é variável, e pode ocorrerr desde formas severas de evolução rápida, com dores abdominais intensas, à manifestações crônicas ou ainda assintomáticas, que só são diagnosticadas através da expulsão de larvas vivas pela a tosse, vômitos ou defecação (TORRES et al. 2000).

No entanto, estudos mostram que a ingestão de larvas mortas pode provocar reações alérgicas em pessoas sensíveis. Alonso et al. (1999) descrevem que a ingestão de peixe infestado com larvas de nematóides da família Anisakidade pode desencadear reações mediadas por Imunoglobulina $E(\lg E)$ e hipersensibilidade do tipo IV (reação tardia), que se caracterizam pela presença de granuloma eosinofílico com ou sem a presença de larvas. Adicionado a esses fatores, pode acarretar alergia gastrintestinal, urticária, eczemas, vômitos, conjuntivite, dermatite de contato, úlceras gástrica e/ou intestinal, podendo determinar um choque anafilático e morte.

Neste contexto, Ubeira et al. (2000) definem a anisakiose como uma enfermidade resultante da combinação da ação direta da larva durante a invasão 
dos tecidos e as interações entre o sistema imunológico do hospedeiro e as substâncias liberadas ou presentes no parasita.

Entretanto, a sintomatologia clínica variada e inespecífica favorece a subnotificação ou diagnóstico incorreto dos casos de anisaquiose, diminuindo os índices epidemiológicos. Acredita-se que, com uma maior vigilância, os casos de notificação se tornariam abundantes (LÓPEZ SERRANO et al., 2000; SABATER e SABATER, 2000; BARROS et al., 2006; PRADO e CAPUANO, 2006).

Diversas espécies de peixes marinhos de importância comercial foram descritos como parasitados por larvas de anisaquídeos, causando um prejuízo econômico estimado entre doze a 50 milhões de dólares ao ano para indústria da pesca na Islândia e Canadá (SABATER e SABATER, 2000).

No Brasil existem diversos trabalhos que relatam a presença de anisakídeos em peixes teleósteos. Em 1995 São Clemente et al. (1995b) reportaram uma prevalência de $20 \%$ de Anisakis spp., $70 \%$ de Pseudoterranova sp. e $100 \%$ de Contracaecum sp. em peixe espada (Trichiurus lepturus). Em 2004 Luque e Poulin (2004) constataram a presença de larvas de anisaquídeos em 44 espécies de peixes marinhos capturados no litoral do estado do Rio de Janeiro.

No entanto, ocorrem variações quanto a prevalência e intensidade de infecção de peixes infectados por anisaquídeos em função dos hábitos alimentares, épocas do ano e distribuição geográfica dos invertebrados e vertebrados marinhos que atuam como hospedeiros destes parasitos (WOOTTEN e WADDELL, 1971 apud CORRES et al. 2001). O mesmo podemos dizer sobre o grau de invasão e distribuição de larvas na musculatura, que varia conforme a espécie, tamanho e idade do peixe. A região muscular mais próxima da cavidade celomática, geralmente é mais infestada por Anisakis simplex, enquanto as larvas de Pseudoterranova decipiens apresentam uma distribuição uniforme em toda a musculatura (SABATER e SABATER, 2000).

\subsubsection{Anisakis spp.}

O gênero Anisakis spp. foi descrito pela primeira vez em 1933, por Remotti (1933) parasitando Merlucius merlucius, após ter sido proposto por Dujardin, em 1845, como subgênero de Ascaris, para acomodar espécies que apresentavam 
espículos desiguais, tendo seu status estabelecido por Railliet e Henry, em 1912 (SMITH e WOOTTEN, 1978; TAVARES e LUQUE, 2006).

Atualmente sua forma larvar já foi descrita em centenas de espécies de peixes marinhos. Sua forma adulta habita o estômago e intestino delgado de mamíferos marinhos ictiófagos como baleias, golfinhos, focas, morsas e leõesmarinhos, particularmente nas águas polares e nas regiões mais frias das zonas temperadas. Ovos não embrionados produzidos pela fêmea adulta são eliminados pelas fezes do animal. Ná água tornam-se embrionados e são formadas as larvas de primeiro estágio $\left(L_{1}\right)$, que evoluem até larvas de segundo estágio $\left(L_{2}\right)$, tornando-se nadantes livres. Estas são ingeridas por crustáceos evoluem para larvas de terceiro estágio $\left(L_{3}\right)$ e, através de predação, são transferidas de peixe para peixe.

Apesar de possuírem os mamíferos marinhos como hospedeiros definitivos, ocasionalmente podem ser encontrados em peixes de água doce, que supostamente tenham sido alimentados de dejetos marinhos infestados e não tratados. Prática comum em navios-fábrica, que eliminam no mar os rejeitos da evisceração, que terminam ingeridos por mamíferos marinhos, completando o ciclo do parasito (SABATER e SABATER, 2000).

A identificação das larvas L3 do gênero Anisakis baseia-se na presença de cutícula com suave estria transversal; três lábios com um dente larvar entre os lábios ventrolaterais e um poro excretor logo abaixo; esôfago com ventrículo posterior, alongado, sigmóide ou aproximadamente esférico; apêndice ventricular e ceco intestinal ausentes; cauda cônica com presença de mucron (SMITH e WOOTTEN, 1978; TIMI et al., 2001).

\subsubsection{Contracaecum spp.}

Os nematóides do gênero Contracaecum se caracterizam por possuírem lábios bem desenvolvidos, edentados, e com a presença de interlábios; poro excretor situado próximo à base dos lábios subventrais; ventrículo pequeno e esférico ou subesférico; ceco intestinal e apêndice ventricular presentes (YORKE e MAPLESTONE, 1926; MOSGOVOY, 1951; HARTWICH, 1974; VICENTE et al.,1985).

O primeiro relato oficial do gênero Contracaecum ocorreu em 1932 na Rússia, 
e desde então diversos autores têm relatado o parasitismo por larvas de terceiro estágio $\left(L_{3}\right)$ em peixes marinhos, de águas salobas e também de águas doces (MARGOLIS, 1977). Registros da ocorrência de larvas de Contracaecum sp. parasitando peixes marinhos no litoral do estado do Rio de Janeiro foram descritos por Rego e Santos (1983), Rego et al. (1983), Barros e Amato (1993), Barros (1994), São Clemente et al. (1994; 1995b), Silva e São Clemente (2001), Luque e Poulin (2004) e Knoff et al. (2007).

Embora as consequências clínicas da ingestão humana de larvas de Contracaecum spp. ainda não tenham sido investigadas, Barros et al. (2007) relatam que o potencial patogênico dessa espécie é comprovada em mamíferos infectados experimentalmente, justificando-se, a necessidade de inspeção prévia do pescado parasitado quando destinado ao consumo humano.

\subsubsection{Pseudoterranova spp.}

Os nematóides do gênero Pseudoterranova frequentemente são incriminados em casos de anisakiose humana. Em 2001, Mercado et al. (2001) relataram a presença de uma larva, de aproximadamente $3 \mathrm{~cm}$, com cabeça e parcialmente aderida na mucosa da hérnia hiatal de uma mulher de 60 anos. No entanto as larvas de Pseudoterranova spp. são caracterizadas como menos invasivas e menos patogênicas do que as do gênero Anisakis.

No litoral do estado do Rio de Janeiro, diversos autores relataram o parasitismo de peixes marinhos por larvas de Pseudoterranova spp. (REGO e SANTOS, 1983; REGO et al., 1983; SÃO CLEMENTE et al., 1994 e 1995b; LUQUE e POULIN, 2004; KNOFF et al., 2007).

As larvas do gênero Pseudoterranova apresentam cutícula com estria transversal e irregular; lábios pouco dilatados anteriormente com margens denteadas e interlábios ausentes; um dente larvar; poro excretor localizado próximo à base dos lábios subventrais; glândula excretora situada ventralmente, se estendendo posteriormente sem atingir o intestino; porção localizada próximo à metade do esôfago larga, com diâmetro correspondendo entre 25-31\% do diâmetro do corpo; ceco intestinal bem desenvolvido e apêndice ventricular ausente. 
Presença de mucron na cauda (GIBSON, 1983; HURST, 1984; VICENTE et al., 1985).

\subsubsection{Cestóides}

Os helmintos da Classe Cestoda caracterizam-se por serem endoparasitos de ciclo evolutivo complexo, envolvendo quase sempre mais de dois hospedeiros, representados pelos crustáceos como hospedeiros intermediários e peixes, aves e mamíferos, como possíveis hospedeiros definitivos. As larvas comumente se encistam nas vísceras e mesentério e os adultos habitam o lúmen intestinal ou cecos pilóricos (EIRAS, 1994; HUSS, 1997; PAVANELLI et al., 1998).

Sob o ponto de vista de saúde pública, a diphyllobotriose é a antropozoonose, causadas por cestóides, mais importante, principalmente em países ou regiões onde existe o hábito de comer peixes crus (BARROS et al., 2002), pois o parasita Diphyllobothrium sp. tem o homem como um dos hospedeiros definitivos (UKUMURA et al., 1999).

Porém, sob o ponto de vista higiênico-sanitário, os cestóides da ordem Trypanorhyncha merecem destaque.

A ordem Trypanorhyncha é composta por uma grande diversidade de famílias, todas parasitas de peixes e invertebrados marinhos. Os helmintos adultos habitam o trato gastrintestinal de peixes elasmobrânquios, enquanto suas formas larvais são encontradas em várias espécies de peixes teleósteos, elasmobrânquios e uma variedade de invertebrados marinhos (CAMPBELL e BEVERIDGE, 1994).

No Brasil, os primeiros registros da ordem Trypanorhyncha foram registrados no estado do Pará, onde, em 1850, Diesing (1850) encontrou larvas de Pterobothium crassicolle em banderado (Bagrus marinus). No entanto, um dos primeiros trabalhos que desempenhou grande contribuição aos serviços de inspeção sanitária de pescado no Brasil foi desenvolvido em 1934 por Faria e Silva (1934) onde foi registrada a presença de tripanorrincas em 21 espécies de peixes teleósteos e elasmobrânquios no litoral do Rio de Janeiro. Desde então, diversas pesquisas ganharam impulso em todo o Brasil (SANTOS e ZOGBI, 1971; REGO et al., 1974; CARVAJAL e REGO, 1983). Em 1974, Rego et al. (1974) identificaram a presença de Pterobothrium spp. em Cynoscion leiarchus e São Clemente (1986a, 1986b) em 
corvina, Micropogonias furnier), ambos no estado do Rio de Janeiro, trabalhos estes que serviriam posteriormente, para definir que a espécie deste cestóide tem pouca especificidade parasitária, já que foram encontradas em peixes fluviais, estuarinos e marinhos.

Sob o aspecto higiênico-sanitário esta parasitose ganhou maior importância a partir da década de 1980, com trabalhos realizados por São Clemente (1986a, 1986b, 1987) em M. furnieri, onde foram examinados 1000 exemplares, com uma prevalência de $38 \%$ de parasitismo por Trypanorhyncha. Logo se seguiram contribuições de Amato et al. (1990) em bonito (Katsuwonus pelamis); de São Clemente et al. (1991, 1995, 1997) em bagre (Netuma barba), peixe porco (Balistes vetula) e enchova (Pomatomus saltator), respectivamente; de Silva e São Clemente (2001) em dourado (Coryphaena hippurus) e ariocó (Lutjanus synagris); e Lima (2004) em namorado (Pseudopercis numida) e peixe-sapo (Lophius gastrophysus), todos capturados no litoral do Estado do Rio de Janeiro.

Nas regiões Norte e Nordeste do Brasil destacam-se os trabalhos realizados por Rego (1987), que identificou plerocercos de Pterobothrium crassicolle em dourada (Brachyplatystoma flavicans), piramutaba (B. vaillanti) e banderado (Bagrus marinus); Palm (1997), que estudou a prevalência de cestóides da ordem Trypanorhyncha em peixes comercializados na costa do nordeste do Brasil; e Oliveira (2005) que pesquisou helmintos em peixes oriundos do litoral norte do Brasil, e identificou a presença de Poecilancystum caryophilum em pescada gó (Macrodon acylodon) e pescada amarela (Cynoscion Acoupa), e Pterobothrium heteracanthum, $C$. cracillis e $P$. crassicole em pescada cambuçu ( $C$. virescens) e uritinga (Arius proops).

Mundialmente destacam-se os trabalhos realizados por Yamaguti (1934) e Overstreet (1977) que analisaram a musculatura de 3000 amostras de nove espécies de peixes Sciaenidae no golfo do México, encontrando quatro espécies de Trypanorhyncha: Poecilancistrium caryophyllum, Pseudogrillotia pleistacantha, Pterobothrium heteracanthum e Pterobothrium lintoni. Com uma prevalência acima de $49 \%$ em Cynoscion nebulosus, o autor sugeriu que o $P$. caryophyllum é um dos mais comuns Trypanorhynchas parasitas de peixes do nordeste do Golfo do México.

Atualmente, além da prevalência e índice médio de infecção, a localização das larvas no corpo dos hospedeiros tem despertado a atenção de muitos autores, principalmente ao considerar a localização muscular como um fator favorecedor da 
infecção por seres humanos. Diversos relatos indicam que a presença de larvas plerocercóides é mais freqüente na cavidade geral e serosa dos órgãos internos, sendo raramente encontradas na musculatura dos peixes (AMATO et al., 1990; SÃO CLEMENTE et al., 1991; SÃO CLEMENTE et al., 1995a; PALM, 1997; SÃO CLEMENTE et al., 1997). Entretanto, as espécies do gênero Pterobothrium, como $P$. kingstoni, $P$. crassicolle e $P$. heteracanthum e dos gêneros Callitetrarhynchus e Otobothrium são incriminadas como invasoras de musculatura de peixes (SÃO CLEMENTE et al., 1991; SÃO CLEMENTE et al., 1995a; PALM, 1997; SÃO CLEMENTE et al., 1997; SILVA e SÃO CLEMENTE et al., 2001). Conforme relatado por Overstreet (1977), que observou que, em peixes Sciaenidae, a localização de plerocercóides de $P$. caryophyllum ocorreu com maior frequência no centro da musculatura corporal, seguido das áreas adjacentes à coluna vertebral, e em menor intensidade na musculatura abdominal.

Em muitas espécies de peixes teleósteos é comum observar altas taxas de infecção na musculatura. No entanto, sabe-se que os cistos de Trypanorhyncha não são transmissíveis aos vertebrados homeotérmicos e o reencapsulamento das póslarvas não ocorre em animais de sangue quente (DOLLFUS, 1942). Na literatura há relatos de apenas três casos de parasitismo em seres humanos, dois por Hepatoxylon trichiuri, com os helmintos encontrados vivos nas fezes, (HEINZ, 1954; FRIPP e MASON, 1983) e um por Nybelinia surmenicola no palato mole de um homem no Japão (KIKUCHI et al., 1981). Recentemente, Vázquez-López et al. (2001) atribuiu o parasitismo pelo cestóide Gymnorhynchus gigas em Brama raji à danos à saúde humana, devido à componentes antigênicos presentes nas larvas do parasito, que são capazes de provocar episódios anafiláticos, induzindo o desenvolvimento de resposta imunitária humoral com desordens alérgicas ou modulação da atividade colinérgica, originando importantes alterações da motilidade e do trânsito intestinal.

A alta taxa de parasitismo na musculatura dos peixes frequentemente os torna impróprios para o consumo, sendo condenados pelos órgãos de fiscalização (BRASIL, 1952), e rejeitados pelo consumidor.

Morfologicamente, os membros da ordem Trypanorhyncha se caracterizam pela presença, de quatro tentáculos eversíveis no ápice do escólex, que sustentam um complexo de diversos ganchos utilizados para a fixação dos helmintos adultos no trato gastrointestinal de seus hospedeiros definitivos. O estágio larval, conhecido 
como plerocerco ou pós-larva, é encontrado nas cavidades corpóreas de peixes teleósteos, crustáceos ou, mais raramente, de répteis (DOLLFUS, 1942).

\subsubsection{Trematódeos}

Os trematódeos digenéticos são helmintos endoparasitos de vertebrados, que caracterizam-se por apresentar órgãos de fixação musculares pouco desenvolvidos e ciclo biológico indireto, podendo incluir até dois hospedeiros intermediários e as aves como o mais comum hospedeiro definitivo. Os moluscos atuam como primeiro hospedeiro intermediário, e os peixes podem atuar tanto como segundo hospedeiro intermediário (portando metacercárias) quanto como hospedeiros definitivos. Entretanto, são mais patogenicamente acometidos quando atuam como hospedeiros intermediários, onde as metacercárias migram pelos tecidos até alcançarem o sítio de infecção, onde permanecem de forma encistada, determinando graves lesões teciduais durante a migração e ao se encistarem (LUQUE, 2004; TAKEMOTO et al., 2004).

No ciclo biológico do parasita, ovos férteis são liberados pelos adultos que parasitam o hospedeiro definitivo (ave piscívora). Uma vez na água, eclodem liberando o miracídio que penetra no molusco, onde evolui até a forma de cercária. Após ser liberada na água a cercária penetra no peixe de água doce, onde evolui até a forma de metacercária dentro de cistos. Quando o peixe parasitado é consumido pela ave, a metacercária é liberada do cisto e evolui até a forma adulta na boca da ave, completando o ciclo.

A maioria das espécies com importância patogênica pertencem às famílias Diplostomidae e Clinostomidae, cujas metacercárias permanecem encistadas na superfície corporal e de órgãos internos dos peixes, provocando diversas lesões, como cataratas e proeminências amareladas (EIRAS et al., 1999; SANTOS et al., 2002; DIAS et al., 2003).

Em registros de parasitismo humano as espécies pertencentes à subordem Digenea são as mais comumente incriminadas, entretanto, essas infecções são raras e ocasionais, e de baixa patogenicidade, exceto em casos de alta infestação (EIRAS, 1994). 
As espécies Diplostomum spathaceum, Clinostomum complanatum e Phagicola longa são as mais importantes sob o ponto de vista de saúde pública, sendo a última responsável por elevados percentuais de infecção em tainhas, paratis e paratis-pema, sendo registrados 11 casos humanos de infecção por esse trematódeo no Brasil (BARROS et al., 2002).

As metacercárias de Clinostomum complanatum são comumente encontradas encistadas na musculatura de peixes teleósteos. Quando em pequena quantidade passam desapercebidas e muitas vezes não são descartadas pelo consumidor ou condenadas pelos órgãos de fiscalização. Uma vez consumido crú, o pescado infectado pode causar laringofaringite e até a morte por asfixia, uma vez que as larvas são capazes de infectar a cavidade oral de seres humanos (EIRAS, 1994; KITAGAWA et al., 2003; CHAN-WOONG et al., 2009). No Brasil, a presença de metacercárias de Clinostomum em peixes de água doce foi relatada por diversos autores, no entanto não há relato de casos em humanos (FERRE, 2001).

\subsection{MEDIDAS DE CONTROLE E PREVENÇÃO DE ZOONOSES PARASITÁRIAS}

Os casos de infecção humana por parasitas de pescado estão comumente associados ao consumo de produtos crús, entretanto, Smith e Wootten (1978) acreditam que a resistência das larvas de anisaquídeos à diferentes tipos de conservação/processamento, pode estar relacionada com as metodologias utilizadas, os tamanhos dos peixes e a localização dos parasitos nos mesmos. São Clemente et al. (1993b) e Oliveira et al. (2004) citam que alimentos mal cozidos, defumados a frio, inadequadamente salgados e refrigerados também podem ser vinculadores de anisakiose.

A aplicação do tratamento térmico comumente destrói a maioria dos microrganismos patogênicos, entretanto deve-se atentar para o tempo e temperatura suficientes para eliminação de cada agente (GERMANO e GERMANO, 2001).

Estudos demonstram que as larvas de anisakídeos são sensíveis ao tratamento térmico. O congelamento do pescado, por tempo e temperatura suficientes, promove a morte das larvas de Anisakis sp., sendo portanto um procedimento importante para a prevenção da infecção humana, porém, fatores como a temperatura do congelador, peso dos peixes e tempo de exposição, influenciam o alcance da temperatura ideal nos pescados armazenados (WHARTON 
e ALDERS, 2002). Neste contexto, estudos de São Clemente et al. (1994) e Marques et al. (1995) demonstraram que o resfriamento a $0{ }^{\circ} \mathrm{C}$ por até 120 horas e o congelamento a $-18{ }^{\circ} \mathrm{C}$ por mais de 24 horas não foram eficientes na inativação de $100 \%$ das larvas de anisakídeos presentes em Pagrus pagrus e Trichiurus lepturus.

Diversos países adotam o congelamento como forma de controle da anisakiose. Nos Estados Unidos, a Agência de Controle Norte-Americana para os Medicamentos e Alimentos (FDA, 2001) recomenda o congelamento à temperatura de $-20 \stackrel{\circ}{\circ}$ por sete dias ou à $-35^{\circ} \mathrm{C}$ por 15 horas, para a destruição de larvas de nematóides; enquanto a Comunidade Econômica Européia (CEE, 2002), recomenda que todo pescado destinado ao consumo in natura ou parcialmente cozido, seja previamente congelado à uma temperatura igual ou inferior a $-20{ }^{\circ} \mathrm{C}$ por, no mínimo, 24 horas.

Com a adoção destas medidas, alguns países europeus observaram uma considerável redução no número de casos de anisaquiose (VALLS et al., 2005).

Assim como a aplicação do frio, a utilização do calor é outra medida que assegura a destruição de larvas de nematóides. Como tempo e temperatura ideais, recomenda-se que a temperatura interna do pescado atinja $60^{\circ} \mathrm{C}$ ou mais, por um período mínimo de dez minutos. (FDA, 2001; PRADO e CAPUANO, 2006).

No entanto, a utilização do forno de microondas como forma de aquecimento deve ser visto com cautela, pois ele não é capaz de garantir uma temperatura homogênea em todos os pontos do pescado ao mesmo tempo. Estudos demonstram que para inviabilizar $100 \%$ das larvas de $A$. simplex na cocção de filés de alabote dente-curvo (Atheresthes stomias) em forno microondas, faz-se necessário que a temperatura interna chegue à $77^{\circ} \mathrm{C}$, na porção mais espessa. (BOUREE et al., 1995; ADAMS et al., 1999; ZULOAGA et al., 2004).

Deve-se atentar que tanto a cocção quanto o congelamento do pescado não são capazes de previnir a ocorrência de reações alérgicas, uma vez que já foi provada a termoestabilidade dos alérgenos mediante prick teste e imunblotting (AUDICANA et al., 1997; CORRES et al., 2001).

Outras medidas de controle como a salga e defumação também podem ser utilizadas. A utilização de altas concentrações de cloreto de sódio ( $\mathrm{NaCl}$ ) pode ser capaz de inativar larvas de anisaquídeos. São Clemente et al. (1996) relataram que 72 horas em salmoura é o tempo necessário para morte das larvas de anisakídeos. Karl et al. (1994) observaram ser necessário um período superior a 17 semanas para 
a inativação de $100 \%$ das larvas de Anisakis sp. em filés de arenque com o uso de $4-5 \%$ de $\mathrm{NaCl}$; de dez a doze semanas com $6-7 \%$ de $\mathrm{NaCl}$ e de cinco a seis semanas com $8-9 \%$ de $\mathrm{NaCl}$. A utilização de salmouras com elevadas concentrações de ácido acético podem assegurar a morte das larvas (SÁNCHEZMONSALVEZ et al., 2005).

$\mathrm{Na}$ defumação à frio, onde a temperatura no interior da massa muscular não supera os $40{ }^{\circ} \mathrm{C}$, ainda existe a possibilidade de sobrevivência de larvas de anisaquídeos e portanto, esta só deve ser utilizada em pescado previamente congelado a $-20{ }^{\circ} \mathrm{C}$ por mais de 24 horas (CEE, 2002).

A utilização de um tratamento suave a altas pressões (140-200 megapascales) durante dez a 15 minutos, permite a morte de Anisakis spp., sendo desnecessário o seu prévio congelamento a $-20{ }^{0} \mathrm{C}$ por 24 horas. Embora exija a utilização de equipamentos mais caros e mão de obra qualificada, este processo agiliza o processamento tecnológico e diminui os gastos com energia (MOLINAGARCIA e SANZ, 2002).

No entanto, apesar de diversas técnicas permitirem a inativação das larvas, a melhor forma de controle das zoonoses parasitárias ainda é a prevenção. Medidas simples como evitar a evisceração do pescado à bordo, já que a presença das larvas de parasitos na musculatura do pescado tem sido relacionada à ingestão dos rejeitos da evisceração por mamíferos marinhos (AMATO e BARROS, 1984; VALLS et al., 2005; PRADO e CAPUANO, 2006); orientar os membros da indústria da pesca quanto as boas práticas de fabricação e manipulação de alimentos; capacitar os fiscais sanitários quanto a correta inspeção do pescado no que tange a prevenção de zoonoses; e conscientizar a população através da realização de campanhas de educação sanitária, alertando quanto aos riscos de ingestão de pescado cru ou insuficientemente cozido; podem minimizar os riscos de infecções parasitárias pela ingestão de pescado contaminado (McCARTHY e MOORE, 2000; SABATER e SABATER, 2000; AUDICANA et al., 2002; BARROS et al., 2006). 


\section{ARTIGOS CIENTífICOS}

Os trabalhos a seguir estão formatados de acordo com as normas das revistas nas quais serão publicados.

3.1 Helmintos de importância higiênico-sanitária em douradas (Brachyplatystoma rousseauxii) capturadas no litoral norte do Brasil. (ACTA AMAZÔNICA)

3.2 Pesquisa de helmintos com potencial zoonótico em tambaquis (Colossoma macropomum) e tucunarés (Cichla spp.) comercializados no sudeste do Pará. (REVISTA BRASILEIRA DE CIÊNCIA VETERINÁRIA)

3.3 Larvas de helmintos de importância higiênico-sanitária em pescada branca (Cynoscion leiarchus) comercializada no sudeste paraense. (REVISTA BRASILEIRA DE PARASITOLOGIA VETERINÁRIA) 
1 Helmintos de importância higiênico-sanitária em douradas,

2 Brachyplatystoma rousseauxii, Castelnau, 1855, capturadas no Pará,

3 litoral norte do Brasil

4

5 Raquel Lima SALGADO', Janaina Barros LUZ², Bruna Menino COSTA²,

6 Irislene Santos PAIVA ${ }^{2}$, Sérgio Carmona de SÃO CLEMENTE ${ }^{3}$

81 Docente do Curso de Graduação em Zootecnia - UFRA/Campus de

9 Parauapebas, Parauapebas-PA

102 Alunos do Curso de Graduação em Zootecnia - UFRA/Campus de

11 Parauapebas, Parauapebas-PA

123 Docente do Programa de Pós-graduação em Higiene Veterinária e

13 Processamento Tecnológico de Produtos de Origem Animal - UFF, Niterói/RJ

15 RESUMO

16 O consumo per capita de peixes no Brasil vem crescendo nos últimos anos. Em

17 muitas espécies de peixes teleósteos é comum observar altas taxas de

18 parasitismo na musculatura, tornando-os impróprios para o consumo. Apesar

19 da importância nutricional e sócio-econômica da pesca para a população

20 paraense, o pescado comercializado no sudeste do Pará ainda é pouco

21 estudado quanto a sua fauna parasitológica. Dentre os peixes de maior

22 importância comercial está a dourada, Brachyplatystoma rousseauxii. Neste

23 contexto, o presente trabalho teve como objetivo avaliar a diversidade da fauna

24 parasitária de interesse comercial e em saúde pública de $B$. rousseauxii. 
25 Durante os meses de janeiro a dezembro de 2009, foram analisados 40 26 exemplares de dourada adquiridos em feiras-livres do município de 27 Parauapebas, quanto a presença de endoparasitos de importância higiênicosanitária. Dos 40 espécimes de dourada analisados, seis encontravam-se 29 parasitados por Anisakis spp. $(\mathrm{P} \%=15 ; \mathrm{IM}=12 ; \mathrm{AM}=1,8)$, um por

30 Poecilancistrium caryophyllum $(\mathrm{P} \%=2,5 ; \mathrm{I}=1 ; \mathrm{A}=0,02)$ e um por

31 Pterobothrium heteracanthum ( $\mathrm{P} \%=2,5 ; \mathrm{I}=1 ; \mathrm{A}=0,02)$. $\mathrm{O}$ reduzido número 32 de estudos da fauna parasitológica de peixes da bacia Amazônica amplamente 33 comercializados em feiras livres, representa risco à saúde humana, e reforçam 34 a necessidade de um maior número de pesquisas nesta região.

35

PALAVRAS-CHAVE: Anisakis spp., parasitos, Brachyplatystoma rousseauxii, Poecilancistrium caryophyllum, Pterobothrium heteracanthum

Helminths of hygienic and sanitary importance in dourada, Brachyplatystoma rousseauxii, purchase on Pará, north coast of Brazil

\section{ABSTRACT}

The per capita consumption of fish in Brazil has been growing in the last years.

4 In many species of teleost fish is common to observe high rates of parasitism in 5 the muscle, making them unfit for consumption. Despite the importance of nutritional and economic status of fisheries for the population of Pará, the fish sold in the southeast of Pará has been few studied for their parasitological fauna. Among the most important commercial fish is dourada, Brachyplatystoma rousseauxii. In this context, this study aimed to evaluate the 
50 diversity of the parasite fauna of commercial interest and public health of $B$.

51 rousseauxii. During the months from January to December 2009 were analyzed 5240 samples of dourada purchased in open-air markets in the city of

53 Parauapebas for the presence of endoparasites with hygienic and sanitary

54 importance. Of the 40 specimens of dourada analyzed, six were parasitized by 55 Anisakis spp. ( $\mathrm{P} \%=15, \mathrm{IM}=12, \mathrm{AM}=1.8)$, one by Poecilancistrium 56 caryophyllum $(\mathrm{P} \%=2.5, \mathrm{IM}=1, \mathrm{AM}=0.02)$ and one by Pterobothrium 57 heteracanthum $(\mathrm{P} \%=2,5, \mathrm{IM}=1, \mathrm{AM}=0.02)$. The few parasitological studies 58 of fish fauna of the Amazon basin widely traded in free markets, represents a 59 risk to human health, and reinforce the need for more research in this area.

61 KEYWORDS: Anisakis spp., Brachyplatystoma rousseauxii, parasites, 62 Poecilancistrium caryophyllum, Pterobothrium heteracanthum

\section{INTRODUÇÃO} Habitante comum das águas doces e de baixa salinidade, a dourada,

65 Brachyplatystoma rousseauxii, é encontrada com frequência na foz e nos 66 canais dos principais rios e afluentes de águas brancas do Amazonas, como os 67 rios Madeira, Japurá, Solimões e Ucayli. É um peixe predador que realiza 68 longas migrações reprodutivas, percorrendo distâncias superiores a 4.000 km, 69 desde o estuário amazônico até a área pré-andina na Colômbia, Peru e Bolívia.

70 As larvas são carreadas rio abaixo pela forte correnteza alcançando o estuário 71 amazônico, seu hábitat natural de crescimento, onde se alimentam de 72 pequenos peixes (Eigemann e Eigenmann 1971; Goulding 1979; Zuanon 1990;

73 Barletta 1995; Barthem e Goulding 1997; Sanyo 1998). 
Economicamente é uma das espécies de bagres de maior importância

75

76 para a pesca da região Norte, sendo capturada comercial e artesanalmente. Sua exploração é feita por frotas pesqueiras de praticamente todas as vilas e cidades ao longo do rio Amazonas e seus principais tributários (Barthem 1992).

A pesca extrativista na região amazônica é favorecida pela matéria orgânica oriunda da decomposição das florestas de mangue e das planícies inundadas do rio Amazonas, carreando sedimentos para a plataforma continental, criando condições propícias para o crescimento e desenvolvimento de diversas espécies de peixes (Nahum 2006).

O peixe de origem continental é fonte de proteína de qualidade acessível para a população de baixa renda e povos indígenas, e se constitui na principal fonte de renda dos moradores de zonas ribeirinhas (Copescal 2005).

Estudos demonstram que a taxa de consumo de pescado na região Amazônica é a maior do mundo, com média estimada em 369 g/pessoa/ dia ou $135 \mathrm{~kg} /$ pessoa/ano, chegando a cerca de $600 \mathrm{~g} /$ pessoa/dia ou $219 \mathrm{~kg} / \mathrm{pessoa} /$ ano em certas áreas do Baixo Rio Solimões e Alto Amazonas, muito acima dos 16,6 kg per capita/ano consumidos pela maioria da população mundial (Cerdeira et al. 1997; Batista et al. 2004).

No entanto, grande parte dos pescadores, piscicultores e comerciantes brasileiros desconhecem a existência dos parasitos e a importância do controle zoossanitário para a profilaxia das doenças, além de desconhecer as perdas econômicas que estes podem acarretar.

Em muitas espécies de peixes teleósteos é comum observar altas taxas de parasitismo na musculatura, tornando-os impróprios para o consumo, sendo 
98 condenados pelos órgãos de fiscalização (Brasil 1952), e rejeitados pelo

99 consumidor. Dentre os parasitos comumente implicados nesse tipo de 100 condenação estão os cestóides da ordem Trypanorhyncha.

101 A ordem Trypanorhyncha é composta por uma grande diversidade de

102 famílias, todas parasitas de peixes e invertebrados marinhos. Os helmintos

103 adultos habitam o trato gastrintestinal de peixes elasmobrânquios, enquanto

104 suas formas larvais são encontradas em várias espécies de peixes teleósteos,

105 elasmobrânquios e uma variedade de invertebrados marinhos (Campbell e 106 Beveridge 1994).

107 Entretanto, sabe-se que os cistos de Trypanorhyncha não são 108 transmissíveis aos vertebrados homeotérmicos e o reencapsulamento das pós-

109 larvas não ocorre em animais de sangue quente (Dollfus 1942). Porém, 110 recentemente, Vázquez-López et al. (2001) atribuiram o parasitismo pelo 111 cestóide Gymnorhynchus gigas em Brama raji à danos à saúde humana, 112 devido a componentes antigênicos presentes nas larvas do parasito, que são 113 capazes de provocar episódios anafiláticos, induzindo o desenvolvimento de 114 resposta imunitária humoral com desordens alérgicas ou modulação da 115 atividade colinérgica, originando importantes alterações da motilidade e do 116 trânsito intestinal.

117 Dentre os parasitos com potencial zoonótico os nematóides da família 118 Anisakidae são os mais implicados em casos de infecção por consumo de 119 pescado.

120 A família Anisakidae é considerada a maior dentro da superfamília 121 Ascaridoidea, e inclui espécies que parasitam peixes, répteis, mamíferos e 
122 aves piscívoras (Anderson 2000). Todos os seus representantes são

123 dependentes do ambiente aquático para o desenvolvimento de seu ciclo

124 biológico, que usualmente envolvem invertebrados e peixes como hospedeiros

125 intermediários ou paratênicos. Anisakis adultos habitam o trato digestivo de

126 mamíferos marinhos, mas suas formas larvares desenvolvem-se no tubo

127 digestivo, musculatura ou cavidade celomática de pequenos peixes, crustáceos

128 ou cefalópodes. O homem se infecta ao ingerir peixes crus ou mal cozidos,

129 ligeiramente curado e/ou condimentado, contendo larvas de anisakídeos (Smith

130 e Wootten 1978; Valls et al. 2005). Estas podem se fixar na mucosa dos

131 órgãos, determinando lesões em diferentes pontos do trato gastrintestinal, ou

132 ainda migrar para localizações extragastrintestinais. Embora comumente

133 associada à ingestão de larvas vivas, estudos recentes mostram que a

134 ingestão de larvas mortas pode provocar reações alérgicas em pessoas

135 sensíveis, acarretando alergia gastrintestinal, urticária, eczemas, vômitos,

136 conjuntivite, dermatite de contato, úlceras gástrica e/ou intestinal, podendo

137 determinar um choque anafilático e morte (Alonso 1999).

138 Embora no Brasil ainda não tenha sido descrito nenhum caso de

139 anisakiose, com a popularização da culinária japonesa e o aumento no número

140 de estabelecimentos de alimentos de origem oriental, esse risco é iminente.

141 Neste contexto, o presente trabalho teve como o objetivo avaliar a 142 diversidade da fauna parasitária de importância higiênico-sanitária em 143 douradas (Brachyplatystoma rousseauxii) capturadas no litoral norte do Brasil, 144 e determinar a prevalência, intensidade de infecção, intensidade média de 145 infecção e abundância média dos parasitos encontrados. 
147 Durante os meses de janeiro a dezembro de 2009, foram analisados 40 148 exemplares de dourada, Brachyplatystoma rousseauxii, medindo entre 37 a 63 $149 \mathrm{~cm}$ de comprimento total (CT), adquiridos em feiras-livres do município de

150 Parauapebas, sudeste do Pará, Brasil. Os peixes foram acondicionados em 151 recipientes isotérmicos com gelo, e transportados até o Laboratório 152 Multidisciplinar do Centro Universitário de Parauapebas - CEUP, vinculado a 153 Universidade Federal Rural da Amazônia (UFRA/Campus de Parauapebas), 154 onde foi realizada a coleta dos parasitos. Uma vez no laboratório os peixes 155 foram pesados, medidos e identificados conforme Figueiredo e Menezes 156 (2000), sendo em seguida eviscerados e inspecionados quanto a presença de 157 parasitos livres ou aderidos à sua cavidade celomática. Em seguida foram 158 filetados e, com auxílio de uma mesa de inspeção ("candling table"), tiveram 159 suas musculaturas avaliadas quanto a presença de parasitos.

160 Com auxílio de um estereomicroscópio, estiletes e agulhas 161 hipodérmicas, as larvas de cestóides da ordem Trypanorhyncha foram 162 liberadas dos seus blastocistos, acondicionadas em placas de Petri contendo 163 água destilada e levadas ao refrigerador por 24 horas, objetivando o 164 relaxamento dos escólices e a extroversão dos tentáculos. Posteriormente, 165 foram fixadas em A. F. A. (95 partes de Álcool 70\% - 5 partes de Formalina - 2 166 partes de Ácido acético) por 24 horas, e mantidas em Etanol a 70\% para serem 167 transportadas até o Laboratório de Tecnologia e Inspeção do Pescado da 168 Universidade Federal Fluminense, onde foram processadas segundo Eiras et al 169 (2006). 
170 As larvas dos nematóides foram acondicionadas em placas de Petri

171 contendo água destilada e posteriormente fixadas em A. F. A. por 24 horas e 172 clarificadas pelo lactofenol de Aman, sendo dispostas entre lâmina e lamínula.

173 A identificação dos nematóides anisakídeos teve como base os trabalhos de 174 Rego et al. (1983) e Petter e Maillard (1988); e Rego (1987) e Campbell e 175 Beveridge (1994) para os cestóides Trypanorhyncha.

176 O cálculo dos índices parasitários de intensidade de infecção, intensidade 177 média de infecção (IM), abundância média ( $A M)$ e prevalência ( $\mathrm{P} \%)$, seguiu a 178 metodologia descrita por Bush et al. (1997).

\section{RESULTADOS E DISCUSSÃO}

Dos 40 espécimes de dourada, Brachyplatystoma rousseauxii, analisados, seis encontravam-se parasitados, por três diferentes espécies de

182 helmintos. Nematóides do gênero Anisakis spp. foram identificados nos seis espécimes parasitados $(P \%=15)$. A intensidade de infecção variou de 03 a 21

184 parasitos por hospedeiro (IM = 12), com abundância média de 1,8 parasitos.

185 Duas espécies de cestóides da ordem Trypanorhyncha foram identificados em 186 apenas um hospedeiro cada: Poecilancistrium caryophyllum $(\mathrm{P} \%=2,5 ; \mathrm{I}=1$;

$187 \mathrm{~A}=0,02)$ e Pterobothrium heteracanthum $(\mathrm{P} \%=2,5 ; \mathrm{I}=1 ; \mathrm{A}=0,02)$. Os índices 188 parasitários de prevalência, intensidade média, amplitude de variação da 189 intensidade e abundância média de infecção, bem como os sítios de infecção 190 estão apresentados na Tabela 1.

191 A presença de larvas de anisakídeos no mesentério e musculatura de 192 peixes teleósteos de origem marinha já foi amplamente descrita, no entanto, 
193 poucos foram os estudos realizados com peixes migratórios da Bacia

194 Amazônica. A dourada (Brachyplatystoma rousseauxii) é um peixe predador,

195 habitante comum das águas de baixa salinidade da foz do Rio Amazonas, que

196 realiza longas migrações reprodutivas. Durante a sua fase de crescimento no

197 estuário amazônico se alimenta de crustáceos e pequenos peixes, que

198 comumente encontram-se parasitados por nematóides.

199 A baixa prevalência de Anisakis spp. e a não observação de larvas vivas

200 no presente estudo, pode estar relacionada à evisceração a bordo e

201 conservação no gelo como formas de conservação do pescado transportado a

202 longas distâncias. Entretanto, não minimizam os riscos de infecção, uma vez

203 que, todos os parasitos encontrados estavam presentes na musculatura, área

204 de maior consumo pela população e de mais difícil identificação de parasitismo.

205 Sabe-se que larvas mortas podem provocar reações alérgicas em pessoas

206 sensíveis, acarretando alergia gastrintestinal, urticária, eczemas, vômitos,

207 conjuntivite, dermatite de contato, úlceras gástrica e/ou intestinal, podendo

208 determinar um choque anafilático e morte (Alonso 1999).

209 Embora no Brasil ainda não tenha sido descrito nenhum caso de

210 anisakiose humana, se considerarmos o alto consumo de pescado na região

211 Amazônica (600 g/per capta/dia) (Cerdeira et al. 1997; Batista et al. 2004), e a

212 a alta taxa de captura (55\% do total de pescado da região do Norte) da

213 dourada (FAO, 2008), o risco de infecções humanas é iminente, principalmente

214 nas populações indígenas e ribeirinhas que têm no peixe a sua principal fonte

215 de proteína animal e na pesca continental sua fonte de renda. 
216 O parasitismo de dourada por ambas as espécies de cestóides

217 identificadas no presente estudo, foi descrito por Silva Júnior et al. (2009) no

218 Amapá, com taxas de prevalência (Pterobothrium heteracanthum $=28,8 \%$ e

219 Poecilancistrium caryophyllum = 3,75\%) e intensidade de média de infecção

220 (Pterobothrium heteracanthum $=5,35$ e Poecilancistrium caryophyllum $=4,33$ )

221 muito acima das encontradas no presente trabalho. Tal variação pode ser

222 explicada em função dos diferentes locais de captura (Belém e Amapá) e dos

223 métodos de manipulação, que neste estudo incluíam a evisceração a bordo

224 como forma de conservação, diminuindo a probabilidade de observação de

225 blastocistos no mesentério dos peixes analisados.

226 No Brasil, os primeiros relatos de parasitos da ordem Trypanorhyncha

227 foram registrados no estado do Pará, Diesing (1850) onde o autor descreve o

228 encontro de larvas de Pterobothium crassicolle em banderado (Bagrus 229 marinus).

230 Rego (1987) retratou a presença de plerocercos de Pterobothrium

231 crassicolle em dourada, Brachyplatystoma rousseauxii. Em 2005 Oliveira

232 (2005) pesquisou helmintos em peixes oriundos do litoral norte do Brasil, e

233 identificou a presença de Poecilancystrium caryophilum em pescada gó,

234 Macrodon acylodon, e pescada amarela, Cynoscion Acoupa, e Pterobothrium

235 heteracanthum, $C$. cracillis e $P$. crassicole em pescada cambuçu, $C$. virescens, 236 e uritinga, Arius proops.

237 Ao contrário dos nematóides anisakídeos, acredita-se que os cestóides 238 da ordem Trypanorhyncha não possuem potencial zoonótico, no entanto alguns 239 registros têm demonstrado que extratos de uma determinada espécie desta 
240 ordem induzem a respostas humorais em camundongos, assim suscitando a

241 possibilidade de ocasionar reações alérgicas em seres humanos (Vásquez-

242 López et al. 2002).

243 Atualmente, além da prevalência e índice médio de infecção, a

244 localização das larvas no corpo dos hospedeiros tem despertado a atenção de

245 muitos autores, principalmente se considerarmos a localização muscular como

246 um fator favorecedor da infecção por seres humanos. Diversos relatos indicam

247 que a presença de larvas plerocercóides é mais frequente na cavidade geral e

248 serosa dos órgãos internos, sendo raramente encontradas na musculatura dos

249 peixes (Amato et al.1990; São Clemente et al. 1991; São Clemente et al. 1995;

250 Palm, 1997; São Clemente et al. 1997). Entretanto, as espécies do gênero

251 Pterobothrium, como $P$. kingstoni, $P$. crassicolle e $P$. heteracanthum e dos

252 gêneros Callitetrarhynchus e Otobothrium são incriminadas como invasoras de

253 musculatura de peixes (São Clemente et al. 1991; São Clemente et al. 1995;

254 Palm, 1997; São Clemente et al.1997; Silva e São Clemente et al. 2001), 255 conforme observado no presente estudo.

\section{CONCLUSÕES}

257 O reduzido número de trabalhos a respeito da fauna parasitária de 258 importância higiênico-sanitária de peixes da bacia Amazônica, aliado a 259 presença de parasitos de conhecido potencial zoonótico em peixes frescos

260 amplamente comercializados em feiras livres, representa um grave risco à 261 saúde humana, e reforçam a necessidade de um maior número de estudos 262 nesta região. 


\section{BIBLIOGRAFIA CITADA}

264 Alonso, A.; Moreno-Ancillo, A.; Daschner, A.; López-Serrano, M.C. 1999.

265 Dietary assesment in five cases of allergic reaction due to gastric anisakiasis.

266 Allergy, 54: 5, 517-520.

267 Amato, J.F.R.; São Clemente, S.C.; Oliveira, G.A. 1990. Tentacularia 268 coryphaenae Bosc., 1801 (Eucestoda: Trypanorhyncha) in the inspection and 269 technology of the skipjack tuna, Katsuwonus pelamis (L.) (Pisces; Scombridae). 270 Atlântica, 12: 73-77.

271 Anderson, R.C. 2000. Nematode parasites of vertebrates. Their development

272 and transmission. 2 ed., London, CAB Publishing. 672 pp.

273 Batista, V.S.; Issac, V.J.; Viana, J.P. 2004. Operation and management of

274 fishery resources in the Amazon, p. 63-152. In: Rufino, M. L. (ed.). A pesca

275 e os recursos pesqueiros na Amazônia brasileira. ProVárzea. Manaus. IBAMA 276 (in Portuguese).

277 Brasil. Ministry of Agriculture, Livestock and Supply. Decree No. 30,691 of 278 March 29, 1952. 2008. Approves the Regulations for Industrial and Sanitary 279 Inspection of Animal Products (RIISPOA). Diário Oficial [da] Federative 280 Republic of Brazil, Brasilia, DF, p.10785, 1952, Section 1. Amended by Decree 281 No. 6385 of February 27, 2008 (in Portuguese). 
282 Bush, A.O.; Lafferty, K.D.; Lotz, J.M.; Shostak, A.W. 1997. Parasitology meets

283 ecology on its own terms: Margolis et al. Revisited. Journal of Parasitology, 83:

$284 \quad 4,575-583$.

285 Campbell, R. A.; Beveridge, I. 1994. Revision of the family Pterobothriidae

286 Pintner, 1931 (Cestoda: Trypanorhyncha). Invertebrate Taxonomy, 10: 617 $287 \quad 662$.

288 Cerdeira, R. G. P.; Ruffino, M. L. E Isaac, V. J. 1997. Fish comsumption and 289 others food itens by the riverine population of the Lago Grande de Monte 290 Alegre, PA - Brazil. Acta Amazônica. 27: 3, $213-228$ (in Portuguese, with 291 abstract in English).

292 Diesing, K. M. 1850. Systema Helminthum. Vindobonae. 679 pp.

293 Dollfus, R. P. 1942. Critical Studies on tétrarhynques Paris Museum. Archives

294 National Museum of Natural History. 19: 1-466 (in French, with abstract in 295 English).

296 Eiras, J.C.; Takemoto, R.M.; Pavanelli,G.C. 2006 Métodos de estudos e 297 técnicas laboratoriais em parasitologia de peixes. 3ª ed. Maringá, Editora 298 Universidade Estadual de Maringá, 189p.

299 FAO. 2009. The State of World Fisheries and Aquaculture - 2008. Rome. 196 p.

300 (http://www.fao.org). Acesso: 19/01/10 (in Spanish).

301 Figueiredo, J.L.; Menezes, N.A. 2000. Handbook of marine fish in Southeast

302 Brazil, vol. VI. São Paulo, Museu de Zoologia, Universidade de São Paulo (in 303 Portuguese). 
304 Nahum, V.J.I. 2006. Operation and Management of Coastal Fisheries

305 Resources of the Amazon: A Challenge To The Future. Ciência e Cultura, 58: 3 306 (in Portuguese).

307 Oliveira, S.A.L. 2005. Survey of helminths in muscle and abdominal serosa 308 of commercially important fish caught along the north coast of Brazil.

309 Dissertação de Mestrado, Universidade Federal do Pará, Pará (in Portuguese , 310 with abstract in English).

311 Palm, H. 1997. Trypanorhynch cestode of commercial fishes from northeast

312 brazilian coastal waters. Memórias do Instituto Oswaldo Cruz. 92:. 1, 69-79 (in

313 Portuguese, with abstract in English).

314 Petter, A.J.; Maillard, C. 1988. Larval Ascarids parasites of fishes from western

315 Mediteranean sea. Bulletin du Museúm National d'Histoire Naturelle. 10:.2, 347-

316369 (in French, with abstract in English).

317 Rego, A.A. 1987. Redescription of Pterobothrium Crassicolle Diesing, 1850

318 (Cestoda: Trypanorhyncha) and revalidation of the species. Memórias do

319 Instituto Oswaldo Cruz. 82: 1, 51-53 (in Portuguese, with abstract in English)

320 Rego, A.A.; Vicente, J.J.; Santos, C.P.; Wekid, R.M. 1983. Parasites anchovies,

321 Pomatomus saltatrix (L.) in Rio de Janeiro. Ciência e Cultura, 35: 9, 1329-1336

322 (in Portuguese).

323 São Clemente, S.C.; Coelho, M.R.T.; Serra-Freire, N.M. 1991. Cestode

324 parasites of catfish Netuma barba (Lacepede, 1803) caught off the coast of Rio

325 de Janeiro and marketed for human consumption. Arquivos da Universidade

326 Federal Rural do Rio de Janeiro. 14:1, 27-34 (in Portuguese). 
327 São Clemente, S.C.; Lima, F.C.; Uchoa, 1995. C.M.A. Balistes vetula parasites

328 and their importance in the inspection of fish. Revista Brasileira de Ciência

329 Veterinária, v. 2, n. 2, 39-41 (in Portuguese).

330 São Clemente, S.C.; Silva, C.M.; Gottschalk, S. 1997. Prevalence and infection

331 intensity of cestodes in Trypanorhyncha Anchovies, Pomatomus saltatrix (L.)

332 from the coast of Rio de Janeiro, Brazil. Parasitol al Día, v. 21, $54-57$ (in

333 Portuguese).

334 Silva Júnior, A.C.S.; Gama, C.S.; Guerreiro, E.G. 2009. Presence of blastocysts

335 in the order of tapeworms in muscle Trypanorhyncha Brachyplatystoma $s p$.

336 (Siluriformes: Pimelodidae), marketed in Macapá-AP and its repercussions on

337 health and trade, In: Anais da $61^{\text {a }}$ Reunião Anual da SBPC, Manaus -

338 Amazonas (in Portuguese).

339 Silva, C. M.; São Clemente, S. C. 2001. Anisakidae family and cestodes of the

340 order in Trypanorhyncha fillets dorado (Coryphaena hippurus) and Arioch

341 (Lutjanus synagris) and its importance for the inspection of fish. Higiene

342 Alimentar, 15: 80/81, 75 - 79 (in Portuguese).

343 Smith, J. W.; Wootten, R. Anisakis and Anisakiasis. 1978. Advances in

344 Parasitology. 16: 93-163.

345 Valls, A.; Pascual, C.Y.; Martín Esteban, M. 2005. Anisakis allergy: an update.

346 Revue française d'allergologie et d'immunologie clinique. 45: 108-113 (in

347 French ).

348 Vázquez-López C, Armas-Serra C, Rodríguez-Caabeiro F. 2001. Gigas

349 Gymnorhynchus: taxonomy, morphology, biology and health aspects. Analecta

350 Veterinaria, 21 (2): 38-49. 
351 Tabela 1- Prevalência (P), intensidade (I), intensidade média (IM), abundância

352 (A), abundância média (AM), amplitude de variação da intensidade de infecção

353 (Al) e sítio de infecção dos helmintos coletados de dourada, Brachyplatystoma

354 rousseauxii, comercializados no sudeste do Pará, entre janeiro a dezembro de

$355 \quad 2009$

\begin{tabular}{lcccccc}
\hline \multicolumn{1}{c}{ Espécie de Parasito } & $\mathrm{P} \%$ & $\mathrm{I}^{*} / \mathrm{IM}$ & $\mathrm{A} / \mathrm{AM}$ & $\mathrm{Al}$ & Sítio de \\
& & & & & Infecção \\
\cline { 2 - 6 } & 15 & 12 & 1,8 & $3-21$ & Musculatura \\
$\begin{array}{l}\text { Anisakis sp. } \\
\text { Poecilancistrium caryophyllum }\end{array}$ & 2,5 & $1^{*}$ & $0,02^{*}$ & - & Mesentério \\
Pterobothrium heteracanthum & 2,5 & $1^{*}$ & $0,02^{*}$ & - & Mesentério \\
\hline
\end{tabular}




\begin{abstract}
Pesquisa de helmintos com potencial zoonótico em tambaquis, Colossoma macropomum, (Cuvier, 1816) e tucunarés, Cichla spp., comercializados no sudeste do Pará/Brasil
\end{abstract}

Helminth larvae with zoonotic potential in tambaqui, Colossoma macropomum, and tucunaré, Cichla spp., purchase in southeast Pará/Brasil

\author{
Raquel Lima Salgado ${ }^{1 *}$, Irislene Santos Paiva ${ }^{2}$, Márcia dos Santos \\ Carvalho $^{2}$, Clarisse da Silva Aguiar ${ }^{2}$, Wíldiney Freire de Oliveira ${ }^{2}$, Sérgio \\ Carmona de São Clemente ${ }^{3}$
}

\title{
Resumo
}

Os peixes são importantes para a dieta das populações rurais e urbanas, no entanto, apresentam uma vasta fauna parasitária, com destaque os nematóides da família Anisakidae. Apesar da grande importância para a saúde e economia local, o pescado comercializado no sudeste paraense ainda é pouco estudado quanto à presença de parasitos de importância higiênico-sanitária. Neste

\footnotetext{
${ }^{1}$ Programa de Pós-Graduação em Medicina Veterinária (Doutorado) - Higiene Veterinária e Processamento Tecnológico de Produtos de Origem Animal Faculdade de Veterinária - Universidade Federal Fluminense.

${ }^{2}$ Curso de Graduação em Zootecnia da Universidade Federal Rural da Amazônia

${ }^{3}$ Departamento de Tecnologia dos Alimentos da Faculdade de Veterinária da Universidade Federal Fluminense. Rua Vital Brazil Filho, 64. Niterói - RJ. CEP 24.230-340.

* A quem enviar a correspondência. E-mail: raquel.salgado@ufra.edu.br; scsc@vm.uff.br
} 
contexto, o presente trabalho objetivou avaliar a diversidade da fauna parasitária de interesse comercial e em saúde pública de duas das principais espécies pesqueiras do sudeste do Pará. Durante os meses de janeiro a dezembro de 2009, foram analisados 40 exemplares de tambaqui, Colossoma macropomum, e 40 exemplares de tucunaré, Cichla spp., adquiridos em feiraslivres do Município de Parauapebas. Foram avaliadas a prevalência (P\%), intensidade média de infecção (IM) e abundância média (AM) dos parasitos encontrados. Não foi encontrada nenhuma espécie de parasito nos 40 exemplares de $C$. macropomum analisados. Onze exemplares de Cichla spp. encontravam-se parasitados, sendo sete por por larvas de nematóides do gênero Contracaecum spp. (P\%17,5, IM1,7 e AM 0,275), e cinco por metacercárias de Clinostomum complanatum (P\%12,5, IM2,5 e AM0,92). Dois dos 11 exemplares encontravam-se parasitados por larvas de ambos os gêneros. Os parasitos encontrados são responsáveis por graves reações alérgicas e gástricas, podendo, inclusive, levar à morte de humanos.

Palavras-chave: Anisakidae, Contracaecum sp., Clinostomum complanatum, potencial zoonótico, Cichla spp., Colossoma macropomum.

\section{Abstract}

Fish are important to the diet of rural and urban populations, however, offer a wide parasitological fauna, especially the Anisakidae family. Despite the importance to health and local economy, the fish sold in the southeast of Pará has been little studied for their parasitological fauna of the sanitary-hygienic importance. In this context, this study analyzes the diversity of the parasite 
fauna of commercial interest and public health from the two main fisheries species in southeastern Pará. During the months of january to december 2009 were analyzed 40 specimens of tambaqui (Colossoma macropomum) and 40 specimens of tucunaré (Cichla spp.) purchased in open-air markets in Parauapebas city. Were evaluated the prevalence (P\%), mean intensity of infection (IM) and mean abundance (MA) of parasites. There was not a parasite species in 40 specimens of $C$. macropomum analyzed. Eleven specimens of Cichla spp. found to be infected, with seven per Contracaecum spp. (P\%17,5, IM1,7 e AM 0,275), and five for trematode Clinostomum complanatum (P\%12,5, IM2,5 e AM0,92). Two of eleven specimens were parasite for both species. This parasites are responsible for severe allergic reactions and stomach and can lead to death.

Keywords: Anisakidae, Contracaecum sp., clinostomum complanatum, zoonotic potencial, Cichla spp., Colossoma macropomum

\section{Introdução}

O consumo per capita de peixes no Brasil vem crescendo nos últimos anos, passando de 6,8 kg/ano em 2003 para 8 kg/ano em 2008 (Seap, 2008). Com isso, o Brasil ganhou espaço como exportador de produtos pesqueiros, sendo o Pará o segundo maior produtor de pescado do país (Ibama, 2007).

A piscicultura na região Amazônica está em constante ascensão, motivada pela diminuição dos estoques pesqueiros e como forma de sustento para populações de baixa renda. Somente no estado do Pará, cerca de 600 ha de área hídrica estão sendo utilizados na implantação de projetos para a criação 
de peixes. Os peixes mais cultivados da bacia Amazônica são o tambaqui (Colossoma macropomum), pirarucu (Arapaima gigas) e o curimatâ (Prochilodus sp.). Entre os exóticos destaca-se a tilápia. (Orechromis spp.) (Ibama, 2007).

O tambaqui é um dos peixes economicamente mais valiosos da região Amazônica. São habitantes naturais da Bacia Amazônica, contudo nos últimos anos vem sofrendo forte pressão de pesca nos seus estoques naturais. A participação desta espécie na produção total de pescado passou de 10,8\% em 1994 para 6,3\% em 1997 (Graef, 1995). Considera-se que a pesca nativa do tambaqui tenha atingido níveis de sobrexploração, sendo atualmente uma espécie protegida pelo lbama (1996).

A pesca extrativista continental se constitui na principal fonte de renda dos moradores de zonas ribeirinhas. Estudos demonstram que a taxa de consumo de pescado na região Amazônica é a maior do mundo, com média estimada em $135 \mathrm{~kg}$ per capita/ano, chegando a 219 kg per capita/ano em certas áreas do Baixo Rio Solimões e Alto Amazonas, muito acima dos 16,6 kg per capita/ano consumidos pela maioria da população mundial (Cerdeira et al, 1997; Batista et al., 2004).

Prevalece nessas regiões a pesca em pequena escala, onde grande parte do pescado capturado serve para consumo próprio ou é vendido em circunstâncias informais. O peixe de origem continental oferece, na maioria das vezes, a única fonte de proteína de qualidade acessível para a população de baixa renda e povos indígenas (Copescal, 2005). 
Nativo das regiões das Bacias Amazônica e do Araguaia, o tucunaré (Cichla spp.) é um dos principais peixes consumidos na região Norte do país. Atualmente foi introduzido nos reservatórios da bacia do Prata, em algumas áreas do Pantanal, no rio São Francisco e nos açudes do Nordeste. Seu cultivo não é muito comum, sendo a pesca predatória a principal forma de obtenção desses espécimes. Caracterizam-se por serem sedentários e alimentarem-se basicamente de pequenos peixes e camarões (Carvalho - Filho, 1992).

Os peixes coexistem com parasitos e patógenos na natureza, em equilíbrio, porém a intensificação dos cultivos faz com que se rompa o equilíbrio existente na relação parasito-hospedeiro-ambiente possibilitando o surgimento de enfermidades que levam à redução do crescimento e ganho de peso, diminuição da fertilidade e até mortalidades elevadas (Crespo e Crespo, 2003). A poluição ambiental, desmatamento e o aquecimento global influênciam diretamente na qualidade da água, alterando os teores de nutrientes, oxigênio e gás carbônicos dissolvidos, causando estresse, redução da resistência, ferimentos e desenvolvimento de enfermidades no pescado (Snatural, 2009).

Diversos são os grupos de parasitos que apresentam importância na produção e comercialização de peixes. Os endoparasitos (trematódeos, nematóides e cestóides) são apontados como agentes responsáveis por significativos prejuízos econômicos em peixes cultivados (Kim et al., 2002). Entretanto os prejuízos podem ser ainda maiores na comercialização e para saúde do consumidor, em função do aspecto repugnante ocasionado pela presença de cistos macroscópicos, de cestóides e trematódeos, na musculatura; e decorrente do potencial zoonótico que alguns parasitos apresentam. 
A família Anisakidae é considerada a maior dentro da superfamília Ascaridoidea, e inclui espécies que parasitam peixes, répteis, mamíferos e aves piscívoras (Anderson, 2000). O homem atua como hospedeiro acidental, adquirindo a larva através da ingestão de peixes crus ou mal cozidos, ligeiramente curado e/ou condimentado (Smith e Wootten, 1978; Valls et al., 2005).

A ingestão de larvas vivas de anisakídeos pode determinar lesões em diferentes pontos do trato gastrintestinal, ou ainda extragastrintestinais. Quando mortas as larvas podem provocar reações alérgicas em pessoas sensíveis, acarretando alergia gastrointestinal, urticária, eczemas, vômitos, conjuntivite, dermatite de contato, úlceras gástrica e/ou intestinal, podendo determinar um choque anafilático e morte (Alonso, 1999).

As metacercárias de Clinostomum complanatum são comumente encontradas encistadas na musculatura de peixes teleósteos. Quando em pequena quantidade passam desapercebidas, podendo causar laringofaringite e morte por asfixia, ao se encistarem na cavidade oral de seres humanos (Eiras, 1994; Kitagawa et al., 2003; Chan-Woong, 2009).

Neste contexto, o presente trabalho teve como o objetivo avaliar a diversidade da fauna parasitária de importância higiênico-sanitária em tambaquis (Colossoma macropomum) e tucunarés (Cichla spp.) comercializados no sudeste do Pará, e determinar a prevalência, intensidade de infecção, intensidade média de infecção e abundância média dos parasitos encontrados. 


\section{Material e métodos}

Durante os meses de janeiro a dezembro de 2009, foram analisados 40 espécimes de tambaqui, Colossoma macropomum, medindo entre 32 a $45 \mathrm{~cm}$ de comprimento total (CT), e 40 espécimes de tucunarés, Cichla spp., medindo entre 40 a $61 \mathrm{~cm}$ de comprimento total (CT), adquiridos em feiras-livres do município de Parauapebas, sudeste do Pará. Os peixes foram acondicionados em recipientes isotérmicos com gelo, e transportados até o Laboratório Multidisciplinar do Centro Universitário de Parauapebas - CEUP, vinculado a Universidade Federal Rural da Amazônia (UFRA/Campus de Parauapebas), onde foi realizada a coleta dos parasitos. Uma vez no laboratório os peixes foram pesados, medidos e identificados conforme Figueiredo e Menezes (2000), sendo em seguida eviscerados e inspecionados visualmente quanto a presença de parasitos livres ou aderidos à sua cavidade abdominal. Em seguida foram filetados e, com auxílio de uma mesa de inspeção ("candling table"), tiveram suas musculaturas avaliadas quanto a presença de parasitos.

Com auxílio de um estereomicroscópio, estiletes e agulhas hipodérmicas, as metacercárias de trematódeos encistadas na musculatura, foram removidas e acondiconadas em placas de Petri contendo solução $\mathrm{NaCl}$ 0,65\%, fixadas em A.F.A e mantidas em Etanol a 70\%, para serem transportadas até o Laboratório de Tecnologia e Inspeção do Pescado da Universidade Federal Fluminense, onde foram processadas de acordo com Eiras et al. (2006). A identificação dos trematódeos digenéticos seguiu taxonomia descrita por Yamaguti (1961).

As larvas dos nematóides foram acondicionadas em placas de Petri contendo água destilada e posteriormente mortos em A. F. A., fixados por 24 horas e 
clarificadas pelo lactofenol de Aman, sendo dispostas entre lâmina e lamínula e identificadas de acordo com Rego et al. (1983) e Petter e Maillard (1988).

O cálculo dos índices parasitários de intensidade de infecção, itensidade média de infecção (IM), abundância média ( $A M)$ e prevalência ( $P \%)$, seguiu a metodologia descrita por Bush et al. (1997).

\section{Resultados e Discussão}

Dos 40 espécimes de tambaquis, Colossoma macropomum, analisados, nenhum encontrava-se parasitado. Dois gêneros de alto potencial zoonótico foram identificados em 11 dos 40 espécimes inspecionados de tucunaré, Cichla spp. Sete espécimes, com tamanho variando entre 40 e $58 \mathrm{~cm}$, encontravamse parasitados por larvas de Contracaecum spp., com intensidade média de infecção de 1,7, prevalência de 17,5\% e abundância média de 0,275. A presença de metacercárias de Clinostomum complanatum foi observada em cinco dos 40 exemplares (prevalência de 12,5\%), com intensidade de infecção variando entre um e quatro (intensidade média de 2,5). Dois dos 11 exemplares encontravam parasitados por ambos os gêneros. Os índices parasitários de prevalência, intensidade média, amplitude de variação da intensidade e abundância média de infecção, bem como os sítios de infecção podem ser observados na Tabela 1.

Diversos helmintos já foram descritos parasitando tambaquis (Fisher et al., 2003; Belmont-Jégu, et al., 2004). Fisher et al. (2003) relataram a presença de 09 diferentes espécies de parasitos em tambaquis capturados no baixo Rio Amazonas. A não observação de parasitos no presente estudo pode estar 
relacionada com as diferentes procedências dos peixes, os quais foram oriundos de pisciculturas. Entretanto, a aparente ausência de parasitos em tambaquis cultivados não representa uma menor sensibilidade desta espécie à infecções parasitárias, mas sim um indicativo de um bom manejo sanitário.

A ocorrência de infecções parasitárias em tucunarés é amplamente observada, principalmente em decorrência da grande variedade de espécies que compõe o grupo dos tucunarés. No entanto, aparentemente, a diversidade de espécies de parasitas varia conforme a espécie hospedeira, método de criação e local de captura. Takemoto et al. (2009) estudaram a fauna parasitária de peixes do Rio Paraná, e observaram em tucunarés a presença de ambos os parasitos encontrados no presente estudo. Em contrapartida, Araujo et al. (2009), estudando a prevalência de parasitos em tucunarés em ambiente amazônico, não identificaram nenhum caso de infecção por Contracaecum spp. ou Clinostomum complanatum.

Salienta-se que nenhum estudo ainda havia sido realizado na região sudeste do Pará, o que reflete a necessidade constante de uma maior fiscalização e avaliação dos peixes consumidos nesta região.

A presença de larvas de Contracaecum spp. e metacercárias de Clinostomum complanatum em peixes frescos amplamente comercializados na região, representa um grave risco à saúde humana. Diversos casos de infecções humanas por estes parasitos já foram descritos, sendo estes geralmente associados ao consumo de peixes crús ou mal cozidos. Com o constante aumento no número de estabelecimentos de culinária japonesa, este perigo tende a se agravar ainda mais. 


\section{Conclusões}

O reduzido número de trabalhos a respeito da fauna parasitária de importância higiênico-sanitária de peixes da bacia Amazônica, aliado a presença de parasitos de conhecido potencial zoonótico em peixes frescos amplamente comercializados em feiras livres, representam um grave risco à saúde humana, e reforçam a necessidade de um maior número de estudos nesta região.

A capacitação dos fiscais sanitários municipais na inspeção do pescado e campanhas de educação sanitária quanto aos hábitos de higiene e cocção dos alimentos, podem reduzir os riscos de infecções por helmintos.

\section{Referências}

ALONSO, A.; MORENO-ANCILLO, A.; DASCHNER, A.; LÓPEZ-SERRANO, M.C. Dietary assesment in five cases of allergic reaction due to gastric anisakiasis. Allergy, v.54 n.5, p.517-520, 1999.

ANDERSON, R.C. Nematode parasites of vertebrates. Their development and transmission. 2 ed. London: CAB Publishing, 2000. 672 p.

ARAUJO, C.S.O.; BARROS, M.C.; GOMES, A.L.S.; VARELLA, A.M.B.; VIANA, G.M.; SILVA, N.P.; FRAGA, E. C.; ANDRADE, S.M.S. Parasitas de populações naturais e artificiais de tucunaré (Cichla spp.). Revista Brasileira de Parasitologia Veterinária, Jaboticabal, v. 18, n. 1, p. 34-38, jan./mar. 2009. 
BATISTA, V.S.; ISSAC, V.J. e VIANA, J.P. "Exploração e manejo dos recursos pesqueiros da Amazônia".In: Rufino, M. L. (ed.). A pesca e os recursos pesqueiros na Amazônia brasileira. ProVárzea:Manaus. 2004, 268p.

BELMONT-JÉGU, E.; DOMINGUES, M.V.; LATERÇA, M.M. Notozothecium janauachensis n. sp. (Monogenoidea: Dactylogyridae) from wild and cultured tambaqui, Colossoma macropomum (Teleostei: Characidae: Serrasalminae) in Brazil. Zootaxa v.736, p. 1-8, 2004.

BUSH, A.O.; LAFFERTY, K.D.; LOTZ, J.M.; SHOSTAK, A.W. Parasitology meets ecology on its own terms: Margolis et al. Revisited. Journal of Parasitology, v.83, n.4, p.575-583, 1997.

CERDEIRA, R.G.P.; RUFFINO, M.L. e ISAAC, V.J. Consumo de pescado e outros alimentos pela população ribeirinha do lago grande de Monte Alegre, PA. Brasil. Acta Amazônica. v. 27, n.3, p. 213-228, 1997.

CHAN-WOONG, P.; JONG-SOON K.; HYUN-SOO, J.; JIN, K. A Human Case of Clinostomum complanatum Infection in Korea. Korean J Parasitol. v. 47, n. 4, p.401-404, December 2009.

COPESCAL - Reunião da Comissão de Pesca Continental para América Latina, 2005. Disponível em:< http://www.rlc.fao.org/pr/comisiones/copescal/ >Acesso em: 20 de jul de 2009.

EIRAS, J. C. Elementos de Ictioparasitologia. Porto: Fundação Eng. Antonio de Almeida. 1994. 339p. 
EIRAS, J.C.; TAKEMOTO, R.M.; PAVANELLI,G.C. 2006 Métodos de estudos e técnicas laboratoriais em parasitologia de peixes. $3^{\text {a }}$ ed. Maringá, Editora Universidade Estadual de Maringá, 189p.

FIGUEIREDO, J.L.; MENEZES, N.A. Manual de peixes marinhos do Sudeste do Brasil, vol. VI. Teleostei (5). São Paulo: Museu de Zoologia, Universidade de São Paulo, 2000.

FISHER, C.; MALTA, J.C.O.; VARELLA, A.M.B. A fauna de parasitas do tambaqui, Colossoma macropomum (Cuvier 1818) (characiformes:characidae) do médio Rio Solimões, estado do Amazonas (AM), e do baixo Rio Amazonas, estdo do Pará (PA), e seu potencial como indicadores biológicos. Acta Amazônica. v.33, n.4, p. 651-662, 2003.

GRAEF, E.W. As espécies de peixes com potencial para criação no Amazonas. In: VAL. A.L.; HONCZARY, A. Criando peixe na Amazônia. 19.ed. Manaus: INPA, 1995. p.29-43.

IBAMA. Instituto Brasileiro do Meio Ambiente e dos Recursos Naturais Renováveis Portaria no 08 de 02 de fevereiro de 1996. Estabelece normas gerais para o exercício da pesca na bacia hidrográfica do Rio Amazonas. Diário Oficial da União, Brasília, DF, 05 fev. 1996.

IBAMA. Instituto Brasileiro do Meio Ambiente e dos Recursos Naturais Renováveis. Estatística da pesca Brasil 2006 e 2007 - Estatística da pesca marinha e continental nos anos de 2006 e 2007. Disponível em: <https//:www.ibama.gov.br>. Acesso em: 22 jan. 2010. 
KITAGAWA N, ODA M, TOTOKI T, WASHIZAKI S, ODA M, KIFUNE T. Lidocaine spray used to capture a live Clinostomum Parasite causing human laryngitis. American Journal of Otolaryngology; v.24, n.5, p.341-343, 2003.

PETTER, A.J.; MAILLARD, C. Larves d'ascarides parasites de poissons en Mediterrane occidentale. Bulletin du Museúm National d'Histoire Naturelle., v. 10, n.2, p. 347-369, 1988.

REGO, A. A. Redescrição de Pterobothrium crassicolle Diesing, 1850 (Cestoda: Trypanorhyncha) e revalidação da espécie. Mem. Inst. Oswaldo Cruz. Rio de Janeiro: v. 82, n. 1, p. 51-53. 1987.

SEAP - Secretaria Especial de Aquicultura e Pesca 2008. Disponível em: <http://www.seap.pr.gov.br> Acesso em: 24 de jan. de 2010.

SMITH, J.W.; WOOTTEN, R. Anisakis and Anisakiasis. Advances in Parasitology., v. 16, p. 93-163, 1978.

TAKEMOTO, R.M.; PAVANELLI, G.C.; LIZAMA, M.A.P.; LACERDA, A.C.F.; YAMADA, F.H.; MOREIRA, L.H.A.; CESCHINI, T.L.; BELLAY, S. Diversity of parasites of fish from the Upper Paraná River floodplain, Brazil. Brazilian Journal of Biology, p. 691-705, jun, 2009.

VALLS, A.; PASCUAL, C.Y.; MARTíN ESTEBAN, M. Anisakis allergy: an update. Revue française d'allergologie et d'immunologie clinique. v. 45, p.108$113,2005$.

YAMAGUTI, S. Synopsis of the digenetic Trematodes of vertebrates. Tokyo: Keigaku, 1971. v.1 e 2, 1074p. 
Tabela 1. Prevalência (P), intensidade média (IM), abundância média (AM), amplitude de variação da intensidade de infecção (Al) e sítio de infecção dos helmintos coletados de tucunaré, Cichla spp., entre janeiro e dezembro de 2009, no sudeste do Pará

\begin{tabular}{cccccc}
\hline Espécie de Parasito & P\% & IM & AM & Al & $\begin{array}{c}\text { Sítio de } \\
\text { infecção }\end{array}$ \\
Contracaecum spp. & 27,5 & 7,8 & 1,95 & $01-05$ & Mesentério \\
Clinostomum complanatum & 10 & 4,25 & 0,42 & $01-04$ & Musculatura \\
\hline
\end{tabular}




\title{
LARVAS DE HELMINTOS DE IMPORTÂNCIA HIGIÊNICO-SANITÁRIA EM PESCADA BRANCA, Cynoscion leiarchus (Cuvier, 1830) COMERCIALIZADA NO SUDESTE PARAENSE, BRASIL
}

\author{
RAQUEL LIMA SALGADO ${ }^{2}$, ALDEAN DE LIMA NASCIMENTO ${ }^{2}$, MÁRJARA \\ ALYNE MULATO SAMPAIO ${ }^{2}$, IRISLENE SANTOS PAIVA ${ }^{2}$, SÉRGIO \\ CARMONA DE SÃO CLEMENTE ${ }^{3}$
}

\begin{abstract}
SALGADO, R.L.; NASCIMENTO, A.L.; SAMPAIO, M.A.M.; PAIVA, I.S.; SÃO CLEMENTE, S.C. [Larvae of helminthes with hygienic and sanitary importance in pescada branca, Cynoscion leiarchus, purchase in southeast Pará, Brasil] Pesquisa de helmintos de importância higiênico-sanitária em pescada branca, Cynoscion leiarchus, comercializada no sudeste paraense, Brasil. Revista Brasileira de Parasitologia Veterinária, v. x, n. x, p. xx-xx, 2010. Docente do Curso de Graduação em Zootecnia/ (UFRA) Universidade Federal Rural da Amazônia/Campus de Parauapebas, Rua A, s/n, Quadra Especial do CEUP, Cidade Nova, CEP 68.515-000, Parauapebas, PA, Brasil. E-mail:
\end{abstract} raquel.salgado@ufra.edu.br

The fish have a wide parasitological fauna, with emphasis on the cestodes of the order Trypanorhyncha and nematodes of the Anisakidae family. This study aimed to evaluate the diversity of the parasite fauna of commercial interest and public health pescada branca (Cynoscion leiarchus) from open-air markets in the Parauapebas, Pará/Brasil. In the period January to December 2009 were analyzed 40 samples of pescada branca (Cynoscion leiarchus). Were identified two different species of parasites in 15 of 40 specimens analyzed.Anisakis spp. nematodes were observed parasitizing 15 specimens (prevalence of $37.5 \%$ ), with range intensity of infection between three and 42 parasites for fish, mean infection intensity of 18.06, and average abundance of 6.77. Three specimens showed multiple parasitism by Anisakis spp. and Poecilancistrium caryophyllum (prevalence 7.5\%), with range intensity of infection between one and two parasites for fish, mean infection

\footnotetext{
${ }^{2}$ Docente do Curso de Graduação em Zootecnia/ (UFRA) Universidade Federal Rural da Amazônia/Campus de Parauapebas, Rua A, s/n, Quadra Especial, Cidade Nova, CEP 68.515-000, Parauapebas, PA, Brasil

${ }^{2}$ Discentes do Curso de Graduação em Zootecnia da (UFRA) Universidade Federal Rural da Amazônia/Campus de Parauapebas, Rua A, s/n, Quadra Especial, Cidade Nova, CEP 68.515-000, Parauapebas, PA, Brasil

${ }^{3}$ Docente do Programa de Pós-graduação em Higiene Veterinária e Processamento Tecnológico de Produtos de Origem Animal - (UFF) Universidade Federal Fluminense, Rua Vital Brazil Filho, 64, Vital Brazil, CEP 24.230340, Niterói, RJ, Brasil
} 
intensity of 1.3, and average abundance of 0.1 . The high prevalence of parasites with zoonotic potential offer a serious risk to human health. Further studies, health education campaigns and training of fiscal health can minimize this risk.

KEY WORDS: Anisakis spp., Cynoscion leiarchus, Poecilancistrium caryophyllum, Trypanorhyncha, Pará, Brasil.

\section{RESUMO}

Os peixes apresentam uma vasta fauna parasitológica, com destaque para os cestóides da ordem Trypanorhyncha e os nematóides da família Anisakidae. Este trabalho teve como objetivo avaliar a diversidade da fauna parasitária de interesse comercial e em saúde pública de pescadas branca, Cynoscion leiarchus, provenientes de feiras-livres no município de Parauapebas, Pará/Brasil. No período de janeiro a dezembro de 2009 foram analisados 40 exemplares de pescada branca. Foram identificadas duas diferentes espécies de parasitos em 15 dos 40 espécimes de analisados. Nematóides do gênero Anisakis spp. foram observados parasitando 15 exemplares (prevalência de 37,5\%), com intensidade de infecção variando entre três e 42 parasitos por peixe; intensidade média de infecção de 18,06; e abundância média de 6,77. Tres exemplares apresentaram parasitismo múltiplo, por Anisakis spp. e Poecilancistrium caryophyllum (prevalência de 7,5\%), com intensidade de infecção variando entre um e dois parasitos por peixe; intensidade média de infecção de 1,3; e abundância média de 0,1 . A alta prevalência de parasitos com potencial zoonótico em pescadas representa um grave risco à saúde humana. Maiores estudos, campanhas de educação sanitária e a capacitação dos fiscais sanitários podem minimizar esse risco.

PALAVRAS-CHAVE: Anisakis spp., Cynoscion leiarchus, Poecilancistrium caryophyllum, Trypanorhyncha, Pará, Brasil.

A demanda pelo pescado vem crescendo nos últimos anos, impulsionada pelo aumento da população e pela tendência em busca de alimentos saudáveis. O pescado é rico em ácidos graxos essenciais, fonte de proteína de alto valor biológico, e pobre em gorduras saturadas. Entretanto, os peixes podem ser acometidos por uma gama de agentes causadores de enfermidades de origem bacteriana, virótica, fúngica e/ou parasitaria, colocando em risco, a saúde do consumidor (GERMANO et al., 2001). 
Os peixes de origem marinha apresentam uma vasta fauna parasitária, com destaque para os cestóides da ordem Trypanorhyncha que, apesar de não possuírem potencial zoonótico, a carne parasitada apresenta um aspecto repugnante, sendo condenada pela fiscalização sanitária e rejeitada pelo consumidor (CAMPBELL e BEVERIDGE, 1994); e os nematóides da família Anisakidae, cuja larva, quando ingerida pelo homem, pode determinar lesões em diferentes pontos do trato gastrointestinal (KNOFF et al., 2003) ou provocar reações alérgicas em pessoas sensíveis (ALONSO et al., 1999).

Apesar da vasta fauna de peixes da Região Amazônica, e da importância nutricional e sócio-econômica, para a população paraense, o pescado comercializado no sudeste do Pará ainda é pouco estudado quanto a presença de parasitos. Neste contexto, o presente trabalho teve como o objetivo avaliar a diversidade da fauna parasitária de interesse comercial e em saúde pública da pescada branca (Cynoscio nleiarchus), uma das principais espécies pesqueiras comercializadas no sudeste do Pará.

Durante os meses de janeiro a dezembro de 2009, foram analisados 40 espécimes de pescada branca (Cynoscion leiarchus), medindo entre 47 e $61 \mathrm{~cm}$ de comprimento total (CT), adquiridos em feiras-livres do município de Parauapebas. Os peixes foram acondicionados em recipientes isotérmicos com gelo, e transportados até o Laboratório Multidisciplinar do Centro Universitário de Parauapebas - CEUP, vinculado à Universidade Federal Rural da Amazônia (UFRA/Campus de Parauapebas), onde foi realizada a coleta dos parasitos. Os mesmos foram processados segundo metodologia descrita por Eiras et al. (2006), e identificados com base nos trabalhos de Rego et al. (1983) e Petter e Maillard (1988), para os nematóides anisakídeos, Rego (1974) e Campbell e Beveridge (1994) para os cestóides Trypanorhyncha.

O cálculo dos índices parasitários de intensidade de infecção, intensidade média de infecção (IM), abundância média (AM) e prevalência (P\%), seguiu a metodologia descrita por Bush et al. (1997).

Foram identificadas duas diferentes espécies de parasitos em 15 dos 40 espécimes de Cynoscion leiarchus analisados. Nematóides do gênero Anisakis spp. foram observados parasitando 15 espécimes (prevalência de 37,5\%). Três espécimes apresentaram parasitismo múltiplo, por Anisakis spp. e Poecilancistrium caryophyllum (prevalência de 7,5\%). Os índices parasitários de prevalência, intensidade média, amplitude de variação da intensidade e abundância média de infecção, bem como os sítios de infecção estão descritos na Tabela 1.

A ocorrência de anisakídeos em peixes de origem marinha é frequente. Diversas espécies de pescada (Cynoscion spp.) têm sido descritas como hospedeiras de formas larvares de 
anisakídeos e trypanorhynchas (REGO et al., 1974; CARVAJAL e REGO, 1983; PALM, 1997; LUQUE e POULIN, 2004; OLIVEIRA, 2005).

A pescada branca pode ser encontrada do Panamá ao sul do Brasil, sendo mais abundante na região norte do país, onde habitam águas estuarinas, e se alimentam de pequenos peixes e crustáceos. O hábito exclusivamente predador desta espécie é responsável pelas suas altas taxas de prevalência de parasitismo. No entanto podem ocorrer variações quanto a espécie, prevalência e intensidade de infecção parasitária em função do método e local de captura e das diferentes épocas do ano (WOOTTEN e WADDELL, 197 apud CORRES et al. 2001). Fato comprovado no presente estudo, onde a taxa de prevalência e intensidade de infecção foi baixa quando comparada a outras pesquisas na região, no entanto tal fato pode ser atribuído aos métodos de conservação que neste estudo incluíam a conservação no gelo e a evisceração a bordo como forma de conservação, diminuindo a probabilidade de observação de larvas vivas e blastocistos no mesentério dos peixes analisados.

Entretanto, a presença de larvas de Anisakis spp. em pescadas brancas comercializadas frescas em mercados municipais e feiras livres, onde a fiscalização sanitária geralmente é ineficiente, representam um grave risco para saúde do consumidor. Quando ingeridas vivas, causam uma ação traumática ao se aderirem à mucosa do trato gastrintestinal, além de promoverem uma reação imune alérgica pela liberação de substâncias contidas no interior do parasito (ALONSO et al., 1999). Embora o local mais freqüente seja o trato digestivo, algumas larvas podem atravessar a parede gastrintestinal, migrando até assentar-se em localizações ectópicas (KNOFF et al., 2003). Larvas mortas podem provocar reações alérgicas em pessoas sensíveis, acarretando alergia gastrintestinal, urticária, eczemas, vômitos, conjuntivite, dermatite de contato, úlceras gástrica e/ou intestinal, podendo determinar um choque anafilático e morte (DEARDOFF et al., 1984; ALONSO et al., 1999).

Embora ainda não descritos no Brasil, os casos de anisakiose podem se tornar frequentes, principalmente se considerarmos o alto consumo de pescado na região Amazônica (600 g/per capta/dia) (CERDEIRA et al, 1997; BATISTA et al., 2004).

A avaliação visual dos peixes com descarte de espécimes parasitados é recomendada e prevista na legislação de diversos países como o Brasil. Na indústria preconiza-se a utilização da "candling table" para análise do pescado filetado, mas nos mercados e feiras livres esta análise fica a cargo dos fiscais de Vigilância Sanitária do município que, na maioria das vezes, são em pequeno número e despreparados para realização de tal inspeção.

Ciente disto, e com intuito de prevenir o aumento no número de casos de anisakiose humana em função da popularização da culinária oriental, que preza a ingestão de alimentos 
crús, a agência americana "Food and Drug Administration" (FDA, 2001) determinou que todo produto de pescado direcionado ao consumo direto e preparado em temperaturas inferiores a $60{ }^{\circ} \mathrm{C}$ deve ser congelado a $-35{ }^{\circ} \mathrm{C}$ por, no mínimo 15 horas ou a $-20{ }^{\circ} \mathrm{C}$ durante sete dias. Tempo e temperatura suficientes para inativar as larvas de anisakídeos.

Entretanto a realidade nos municípios do interior do Brasil é que peixes frescos comercializados livremente nas feiras e mercados municipais comumente são utilizados no preparo de sushis e sashimis. A população desconhece os riscos da ingestão de pescado crú ou pouco cozido, ficando sujeita a diferentes tipos de parasitoses.

A alta prevalência de parasitos com potencial zoonótico em peixes frescos comercializados nas feiras e mercados nos municípios do interior do Brasil representam um grave risco à saúde humana.

Campanhas de educação sanitária e a capacitação dos fiscais sanitários municipais podem minimizar esse risco.

Maiores estudos devem ser realizados com o pescado comercializado no interior do país.

\section{REFERÊNCIAS BIBLIOGRÁFICAS}

ALONSO, A.; MORENO-ANCILLO, A.; DASCHNER, A.; LÓPEZ-SERRANO,

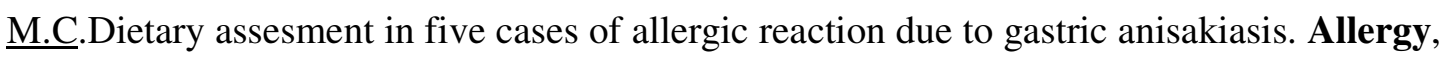
v.54 n.5, p.517-520, 1999.

BATISTA, V. S.; ISSAC, V. J.; VIANA, J. P. "Exploração e manejo dos recursos pesqueiros da Amazônia". In: Rufino, M. L. (ed.). A pesca e os recursos pesqueiros na Amazôniabrasileira. ProVárzea: Manaus. 2004, 268p.

BUSH, A.O.; LAFFERTY, K.D.; LOTZ, J.M.; SHOSTAK, A.W. Parasitology meets ecology on its own terms: Margolis et al. reviseted. Journal of Parasitology, n. 83, n.4, p. 575$583,1997$.

CAMPBELL, R. A.; BEVERIDGE, I. Revision of the family PterobothriidaePintner, 1931 (Cestoda: Trypanorhyncha). Invertebrate Taxonomy., v. 10, p. 617 - 662, 1994.

CARVAJAL, J.; REGO, A. A. Progrillotia dollfusi sp. n. (Cestoda, Trypanorhyncha) parasito de pescado do Litoral Brasileiro. Memórias do Instituto Oswaldo Cruz, v.78, n.2, p. 231234, 1983.

CERDEIRA, R. G. P.; RUFFINO, M. L.; ISAAC, V. J. Consumo de pescado e outros alimentos pela população ribeirinha do lago grande de Monte Alegre, PA. Brasil. Acta Amazônica. v. 27, n.3, p. 213-228, 1997. 
CORRES, L.F.; DEL POZO, M.D.; AIZPURU, F. Prevalencia de la sensibilización a Anisakis simplex en tres áreas españolas, en relación a las diferentes tasas de consumo de pescado. Relevancia de la alergia a Anisakis simplex. AlergolImmunogyClinical, v. 16, p. 337-346, 2001.

DEARDORFF, T.L.; RAYBOURNE, R.B.; MATTIS, T.E. Infections with Trypanorhynchaplerocerci (Cestoda) in Hawaiian fishes of commercial importance. Quarterly University of Hawaiian Sea Grant College Program, v. 6, n. 3, p. 1-6, 1984.

GERMANO, P. M. L.; GERMANO, M. I. S.; OLIVEIRA, C. A. F. Anisaquíase. In: GERMANO, P. M. L.; GERMANO, M. I. S. Higiene e Vigilância Sanitária de Alimentos. São Paulo: Livraria Varela, 2001. Parte 8. p. 115-134.

FDA - Food and Drug Administration. Fish and fishery products hazards and controls guide. 3 ed. Washington DC: FDA - Center for food safety and applied nutrition. 2001.

KNOFF, M.; SÃO ClEMENTE, S. C.; DE LIMA, F. C.; PADOVANI, R. E. S.; DE CASTRO, R. T.; PINTO, R. M.; GOMES, D. C. Helmintos de importância sanitária presentes no Congro-rosa, Genypterus brasiliensis regan, 1903, comercializados no estado do Rio de Janeiro. Revista Higiene Alimentar, v.17, p.226, 2003.

LUQUE, J.L.; POULIN, R. Use of fish a intermediate host by helminth parasites: A comparative analysis. Acta Parasitologica, v. 49, n. 4, p. 353-361, 2004.

MENEZES, N. A.; FIGUEIREDO, J. L. Manual de peixes marinhos do sudeste do Brasil, São Paulo: Universidade de São Paulo, v. 4, n. 3, 1980.

OLIVEIRA, S. A. L. Pesquisa de helmintos em musculatura e serosa Abdominal de peixes de importância comercial capturados no litoral Norte do Brasil. 2005. Dissertação (Mestrado) - Universidade Federal do Pará, Pará.

PALM, H. Trypanorhynchcestode of commercial fishes from northeast brazilian coastal waters. Mem. Inst. Oswaldo Cruz. v. 92, n. 1, p. 69-79, 1997.

PETTER, A.J.; MAILLARD, C. Larves d'ascarides parasites de poissons en Mediterrane occidentale. Bulletin du Museúm National d'HistoireNaturelle., v. 10, n.2, p. 347-369, 1988.

REGO, A. A.; SANTOS, C. P. Helmintofauna de cavalas, Scomber japonicus Houtt, do Rio de Janeiro. Mem. Inst. Oswaldo Cruz, Rio de Janeiro: Instituto Oswaldo Cruz, v. 78, p. 443-448, 1983.

REGO, A. A.; SANTOS, J. C.; SILVA, P. P. Estudo de cestóides de peixes do Brasil. Mem. Inst. Oswaldo Cruz. v. 72, n. 3/4, p. 187-204, 1974. 
Tabela 1. Prevalência (P), intensidade média (IM), abundância média (AM), amplitude de variação da intensidade de infecção (AI) e sítio de infecção dos helmintos coletados de pescada branca (Cynoscion leiarchus), comercializados no sudeste do Pará, entre janeiro a dezembro de 2009

\begin{tabular}{lccccc}
\hline Espécie de parasito & P\% & IM & AM & AI & sítio de \\
& & & & & infecção \\
Anisakis spp. & 37,5 & 18 & 6,7 & $03-42$ & mesentério \\
$\begin{array}{l}\text { Poecilancistrium caryophyllum } \\
\text { Poenculatura }\end{array}$ \\
\hline
\end{tabular}




\section{CONSIDERAÇÕES FINAIS}

O reduzido número de trabalhos a respeito da fauna parasitológica de importância higiênico-sanitária de peixes da bacia Amazônica, aliado a presença de parasitos de conhecido potencial zoonótico em peixes frescos amplamente comercializados em feiras livres, representam um grave risco à saúde humana, e reforçam a necessidade de um maior número de estudos nesta região.

Campanhas de educação sanitária quanto aos hábitos de higiene e cocção dos alimentos podem reduzir os riscos de infecções por helmintos.

Programas frequentes de capacitação dos fiscais sanitários municipais podem minimizar esse risco. 


\section{REFERÊNCIAS BIBLIOGRÁFICAS}

ADAMS, A.M.; MILLER, K.S.; WEKELL, M.M.; DONG, F.M. Survival of Anisakis simplex in microwave-processed Arrowtooth flounder (Atheresthes stomias). Journal of food protection, v.62, n.4, p.403-409, 1999.

ALONSO, A.; MORENO-ANCILLO, A.; DASCHNER, A.; LÓPEZ-SERRANO, M.C. Dietary assesment in five cases of allergic reaction due to gastric anisakiasis. Allergy, v.54, n.5, p.517-520, 1999.

AMATO, J. F. R.; SÃO CLEMENTE, S. C.; OlIVEIRA, G. A. Tentacularia coryphaenae Bosc., 1801 (Eucestoda: Trypanorhyncha) in the inspection and technology of the skipjack tuna, Katsuwonus pelamis (L.) (Pisces; Scombridae). Atlântica, v. 12, p. 73-77, 1990.

AMATO, J.F.R.; BARROS, G.C. Anisaquíase humana no Brasil: problema inexistente ou não pesquisado. Revista Brasileira de Medicina Veterinária, v.6, p.12, 1984.

AMBIENTE BRASIL. Disponível em: http://www.ambientebrasil.com.br. Acesso em: 10/01/2010.

ANDERSON, R.C. Nematode parasites of vertebrates. Their development and transmission. 2 ed. London: CAB Publishing, 2000. 672 p.

AUDICANA, L.; AUDICANA, M. T.; FERNÁNDEZ, L. C.; KENNEDY, M. W. Cooking and freezing may not protect against allergenic reactions to ingested Anisakis simplex antigens in humans. Veterinay Record, v.140, n.235, p. 1997.

AUDICANA, M.T.; ANDOTEGUI, I.J.; CORRES, L.F.; KENNEDY, M.W. Anisakis simplex: dangerous dead and alive? Trends in Parasitology, v. 34, p. 296-302, 2002.

BARLETTA, M. Estudo da comunidade de peixes bentônicos em três áreas do canal principal, próximos a confluência dos rios negro e solimões-amazonas (Amazônia Central - Brasil) Tese de Mestrado, INPA/FUA, Manaus. 1995.

BARROS, G. C. Larvas de anisakídeos de peixes economicamente importantes da costa do Estado do Rio de Janeiro. Revista Brasileira de Medicina Veterinária, v. 16, n. 5, p. 205-208, 1994. 
BARROS, G. C.; AMATO, J. F. R. Larvas de anisakídeos de peixe-espada, Trichiurus lepturus L., da costa do Estado do Rio de Janeiro, Brasil. Revista Brasileira de Biologia, v. 53, p. 241-245, 1993.

BARROS, G. C.; MENDES, E. S.; SANTOS, F. L. Patologia dos peixes. Revista Conselho Federal de Medicina Veterinária, n. 26, p. 44-56, 2002.

BARROS, L. A.; MORAES FILHO, J.; OLIVEIRA, R. L. Larvas de nematódeos de importância zoonótica encontradas em traíras no município de Santo Antônio do Leverger - MT. Arquivo Brasileiro de Medicina Veterinária e Zootecnia, v.59, n. 2, p. 533-535, 2007.

BARROS, L. A.; MORAES FILHO, J.; OLIVEIRA, R.L. Nematóides com potencial zoonótico em peixes com importância econômica provenientes do rio Cuiabá. Revista Brasileira de Ciência Veterinária, v.13, n.1, p.55-57, 2006.

BARTHEM, R. B.; GOULDING, M.. Os Bagres Balizadores: Ecologia, migração e conservação de peixes amazônicos, Sociedade Civil Mamirauá; CNPQ, Brasília p.140, 1997.

BARTHEM, R.B. Desenvolvimento da pesca comercial na bacia amazônica e conseqüências para os estoques pesqueiros e a pesca de subsistência. Série Cooperação Amazônica, n. 13 p. 1-643, 1992.

BATISTA, V. S.; ISSAC,V. J. e VIANA, J. P. "Exploração e manejo dos recursos pesqueiros da Amazônia".In: Rufino, M. L. (ed.). A pesca e os recursos pesqueiros na Amazônia brasileira. ProVárzea:Manaus. 2004, 268p.

BOUREE, P.; PAUGAM, A.; PETITHORY,J.C. Anisakidosis: Report of 25 cases and review of the literature. Comparative Immunology, Microbiology and Infectious Diseases, v.18, n.2, p.75-84, 1995.

BRASIL. Ministério da Agricultura Pecuária e Abastecimento. Decreto n³0691, de 29 de março de 1952. Aprova o Regulamento da Inspeção Industrial e Sanitária de Produtos de Origem Animal (RIISPOA). Diário Oficial União, Brasília, DF, p.10785, 07 jul. 1952, Seção 1. Alterado pelo Decreto n ${ }^{\circ} 6385$, de 27 de fevereiro de 2008.

C. E. E. Segurança alimentar: medidas reforçadas. A pesca na Europa. Publicação da Comissão Européia- direção Geral da Pesca, v.1, n.11, 2002.

CAMPBELL, R. A.; BEVERIDGE, I. Revision of the family Pterobothriidae Pintner, 1931 (Cestoda: Trypanorhyncha). Invertebrate Taxonomy, v. 10, p. 617 -662, 1994.

CARVAJAL, J.; REGO, A. A. Progrillotia dollfusi sp. n. (Cestoda, Trypanorhyncha) parasito de pescado do Litoral Brasileiro. Memórias do Instituto Oswaldo Cruz, v.78, n.2, p. 231-234, 1983.

CERDEIRA, R. G. P.; RUFFINO, M. L. e ISAAC, V. J. Consumo de pescado e outros alimentos pela população ribeirinha do lago grande de Monte Alegre, PA. Brasil. Acta Amazônica, v. 27, n.3, p. 213-228, 1997. 
CHAN-WOONG, P.; JONG-SOON K.; HYUN-SOO, J.; JIN, K. A Human Case of Clinostomum complanatum Infection in Korea. Korean Journal of Parasitology, v. 47, n. 4, p.401-404, 2009.

CHITWOOD, M. Phocanema - type larval nematode coughed up by a boy in California. American Journal Tropical Medicine, v. 24, p. 710-711, 1975.

COPESCAL - Reunião da Comissão de Pesca Continental para América Latina, 2005. Disponível em:< http://www.rlc.fao.org/pr/comisiones/copescal/ >Acesso em: 20 de jul de 2009.

CORRES, L.F.; DEL POZO, M.D.; AIZPURU, F. Prevalencia de la sensibilización a Anisakis simplex en tres áreas españolas, en relación a las diferentes tasas de consumo de pescado. Relevancia de la alergia a Anisakis simplex. Alergol Immunogy Clinical, v. 16, p. 337-346, 2001.

DASCHNER, A.; MORENO, A. A. Anaphylaxis with Anisakis simplex in the gastric mucosa. English Journal Medicine, v. 337, p. 350-351, 1997.

DIAS, M.L.G.G.; EIRAS, J.C.; MACHADO, M.H.; SOUZA; G.T.R.; PAVANELLI, G.C. The life cycle of Clinostomum complanatum Rudolphi, 1814 (Digenea, Clinostomidae) on the floodplain of the high Paraná river, Brazil. Parasitology Research, v. 89, n. 6, p. $506-508,2003$.

DIESING, K. M. Systema Helminthum. Vindobonae, 1850. 679 p.

DOLLFUS, R. Études critiques sur les tétrarhynques du Muséum de Paris. Archives of Museum Noturell. Histoire Noturelle Paris, n. 19, p. 1-466, 1942.

EIGENMANN, C. H.., EIGENMANN, R.S. A revision of South American Nematognathi, or catfishes. Occasional Papers of the California Academy of Sciences, n,1, 1971.

EIRAS, J. C. Elementos de Ictioparasitologia. Porto: Fundação Eng. Antonio de Almeida. 1994. 339p.

EIRAS, J. C.; PAVANELLI, G. C.; RANZANI-PAIVA, M. J. T.; TAKEMOTO, R. M. Gill histopathology of Piaractus mesopotamicus (Osteichthyes: Serrasalmidae) infected by Henneguya piaractus Martins \& Souza, 1997 (Myxozoa; Myxobolidae). Research and Reviewsin Parasitology, v.59, n.3-4, p.117 - 120, 1999.

FABRESSE, F. X. Polyarthrite de l'anisakiase. La Presse Médicale, v.13, p.1004, 1984.

FAO. Food and Agriculture Organization 2001. El estado mundial de la pesca y la acuicultura. Parte 2. Temas de interés para los pescadores y acuicultores. Disponível em: http://www.fao.org/DOCREP/003/X8002S/X8002S00.htm. Acesso em: 08 de julho de 2009

FAO. Food and Agriculture Organization 2006. O Estado Mundial da Pesca e da Aquicultura. Disponível em:< ftp://ftp.fao.org/docrep/fao/009/a0699e/a0699e.pdf> Acesso em: 08 de julho de 2009 
FARIA, A.; SILVA, A. D. Garoupa vermelha de Abrolhos e São Tomé "Garoupa Bichada" Tetrarhynchus (Primeira nota). Rio de Janeiro: Primeiro Congresso Nacional de Pesca, v. 1, p. 237 - 250, 1934.

FDA - Food and Drug Administration. Fish and fishery products hazards and controls guide. 3 ed. Washington DC: FDA - Center for food safety and applied nutrition. 2001.

FERRE I. Anisakiosis y otras zoonosis parasitarias transmitidas por consumo de pescado. Aqua Tec, v.14, p.1-2, 2001.

FERREIRA, A. S. G. A Amazônia que eu não vi, 2006 Disponível em:< http://www.fnt.org.br/artigos.php?id=324\&releitura_id=11 >Acesso em: 20 de jul de 2009.

FERREIRA, E. J. G. Alimentação dos adultos de doze espécies de cichlideos (Perciformes, Cichlidae) do rio negro, Brasil. Manaus: INPA/FUA, 1998, 254p.

FRIPP, P. J.; MASON, P. R. Spurioius Human Infection with a Trypanorhynchiid Tapeworm. South Africa Jornal of Science, v. 79, p. 473, 1983.

GAMA, A. S. P. Diagnóstico da Pesca no Estado do Pará 2008. Disponível em: $<$ http://www.sepaq.pa.gov.br/files/u1/diag_pesca2008.php> Acesso em: 14 de jul. de 2009.

GERMANO, P. M. L.; GERMANO, M. I. S. Anisaquíase: zoonose parasitária emergente no Brasil ? Higiene Alimentar, v.12, n. 54, p. 26-35, 1998.

GERMANO, P. M. L.; GERMANO, M. I. S.; OLIVEIRA, C. A. F. Anisaquíase. In: GERMANO, P. M. L.; GERMANO, M. I. S. Higiene e Vigilância Sanitária de Alimentos. São Paulo: Livraria Varela, 2001. Parte 8. p. 115-134.

GIBSON, D. I. The systematics of ascaridoid nematodes - a current assessment. In: STONE A. R.; PLATT, H. M.; KHALIL, L. F. (eds.) Concepts in nematode systematics. London, Academic Press, 1983. p. 321-338.

GOULDING, M. Ecologia da pesca do rio Madeira. Manaus: INPA, 1979, 172p.

GRAEF, E.W. As espécies de peixes com potencial para criação no Amazonas. In: VAL. A.L.; HONCZARY, A. Criando peixe na Amazônia. 19.ed. Manaus: INPA, 1995. p.29-43.

HARTWICH. G. Keys to genera of the Ascaridoidea. In: ANDERSON; CHABAUD; WILLMOT. (eds.) CIH keys to the nematode parasites of vertebrates. Farnham Royal, Commonwealth Agricultural Bureau, 1974. p. 1-15.

HEINZ, H. J. A case of tetrarhynchid (cestode) infection in man. Revista Ecuatoriana de Entomología e Parasitoogía, v. 2, p. 227-230, 1954.

HUBERT, B.; BACOU, J.; BELVEZE, H. Epidemiology of human anisakiasis: incidence and sources in France. American Journal of Tropical Medicine, v. 40, p. 301-303, 1989. 
HURST, R.J. Identification and description of larval Anisakis simplex and Pseudoterranova decipiens (Anisakidae: Nematoda) from New Zealand waters. New Zealand Journal of marine and Freshwater Research, v.18, p.177-186, 1984.

HUSS, H.H. Garantia da qualidade dos produtos da pesca. FAO - Documento técnico sobre as pescas. n³34. Roma, FAO. 1997. 176p.

IBAMA. Instituto Brasileiro do Meio Ambiente e dos Recursos Naturais Renováveis. Estatística da pesca Brasil 2006 e 2007 - Estatística da pesca marinha e continental nos anos de 2006 e 2007. Disponível em: <https//:www.ibama.gov.br>. Acesso em: 22 jan. 2010.

IBAMA. Instituto Brasileiro do Meio Ambiente e dos Recursos Naturais Renováveis Portaria $\mathrm{n}^{0} 08$ de 02 de fevereiro de 1996. Estabelece normas gerais para 0 exercício da pesca na bacia hidrográfica do Rio Amazonas. Diário Oficial da União, Brasília, DF, 05 fev. 1996.

JENSEN, T.; ANDERSEN, K.; DES CLERS, S. Sealworm (Pseudoterranova decipiens) infections in demersal fish from two areas in Norway. Canadian Journal Zoologic, v. 72, p. 598-608, 1994.

KARL, H.; ROEPSTORFF, A.;HUSS, H.H.; BLOEMSMA, B. Survival of Anisakis larval in marinated herring fillets. International journal of food science and technology, v.29, n.6, p.661-670, 1994.

KATES, S.; WRIGHT, K. A.; WRIGHT, R. A case of human infection with the cod nematode Phocanema sp. American Journal Tropical Medicine. v. 22, p. 606-608, 1973.

KIKUCHI, Y.; TAKENOUCHI, K. M. T.; DZANI, O. Trypanorhyncha cestode larva found on the palatine tonsil. Japanese Journal of Parasitology, v. 30, p. 497- 499, 1981.

KIM, J. H.; HAYWARD, C. J; HEO, G. J. Nematode worm infections (Camallanus cotti, Camallanidae) in guppies (Poecilia reticulata) imported to Korea. Aquaculture, v. 205, p. 231-235, 2002.

KITAGAWA N, ODA M, TOTOKI T, WASHIZAKI S, ODA M, KIFUNE T. Lidocaine spray used to capture a live Clinostomum Parasite causing human laryngitis. American Journal of Otolaryngology, v.24, n.5, p.341-343, 2003.

KLIKS, M. M. Anisakiasis in the Western United States: four new case reports from California. American Journal of Tropical Medicine, v. 32, p. 526-532, 1983.

KNOFF, M.; SÃO CLEMENTE, S.C.; FONSECA, M.C.G.; ANDRADA, C.G.; PADOVANI, R.E.S.; GOMES, D.C. Anisakidae parasitos de congro-rosa, Genypterus brasiliensis Regan, 1903 comercializados no estado do Rio de Janeiro, Brasil de interesse na saúde pública. Parasitologia Latinoamericana, v.62, p.127-133, 2007.

KOBAYASHI, A.; TSUJI, M.; WILBUR, D. L. Probable pulmonary anisakiasis accompanying pleural effusion. American Journal Tropical Medicine, v. 34, p. 310313, 1985. 
KUBITZA, F. O mar está pra peixe, pra peixe cultivado. Panorama da Aquicultura, v.17, n. 100, mar./abr, 2007.

LICHTENFELS, J. R.; BRANCATO, F. P. Anisakid larva from the throat of an Alaskan Eskimo. American Journal Tropical Medicine, v. 25, p. 691-693, 1976.

LIMA, F. C. Cestóides da Ordem Trypanorhyncha em peixes teleósteos comercializados no Estado do Rio de Janeiro. Niterói, 2004. 86 f. Tese (Doutorado em Medicina Veterinária) - Faculdade de Veterinária, Universidade Federal Fluminense, Niterói. 2004.

LITTLE, M.D.; MACPHAIL, J.C. Large nematode larva from the abdominal cavity of a man in Massachusetts. American Journal Tropical Medicine, v. 21, p. 948-950, 1972.

LITTLE, M.D.; MOST, H. Anisakid larva from the throat of a woman in New York. American Journal Tropical Medicine, v. 22, p. 609-612, 1973.

LÓPEZ SERRANO, M.C.; ALONSO-GÓMEZ, A.; MORENO-ANCILLO, Á.; DASCHNER, Á.; SUÁREZ DE PARGA, J. Anisakiasis gastro-alérgica: hipersensibilidad inmediata debida a parasitación por Anisakis simplex. Alergología inmunología clínica, v.15, p. 230-236, 2000.

LUQUE, J. L. Parasitologia de Peixes Marinhos na América do Sul: Estado Atual e Perspectivas. In: RANZANI-PAIVA, M. J. T.; TAKEMOTO, R. M.; LIZAMA, M. A. P. Sanidade de Organismos Aquáticos. São Paulo: Livraria Varela. Parte II. Cap 09. p. 199- 215. 2004..

LUQUE, J.L.; POULIN, R. Use of fish as intermediate hosts by helminth parasites: a comparative analysis. Acta Parasitology, v.49, 353-361, 2004.

MAGGI, P. Gastrointestinal infection due to Anisakis simplex in southern Italy. Europe Journal Epidemiology, v. 16, p.75-78, 2000.

MARGOLIS, L. Public health aspects of "codworn infection". Journal of Fishes Research Bolletim, v. 34, n. 7, p. 887-898, 1977.

MARQUES, M.C.; SÃO CLEMENTE, S.C.; BARROS, G.C.; LUCENA, F.P. Utilização do frio (resfriamento e congelamento) na sobrevivência de larvas de nematóides anisakídeos em Trichiurus lepturus (L.). Higiene Alimentar, v. 9, p. 23-28, 1995.

McCARTHY, J.; MOORE, T.A. Emerging helminth zoonoses. International journal for parasitology, v.30, p.1351-1360, 2000.

MELO, L. A. S.; IZEL, A. C. U.; RODRIGUES, F. M. Criação de tambaqui (Colossoma macropomum) em viveiros de argila/barragens no Estado do Amazonas. Manaus: Embrapa Amazônia Ocidental, 2001. n30 p.18.

MENEZES, N. A.; FIGUEIREDO, J. L. Manual de peixes marinhos do sudeste do Brasil, São Paulo: Universidade de São Paulo,v. 4, n. 3, 1980. 
MERCADO, R.; TORRES, P.; MAIRA, J. Human case of gastric infection by a fourthlarval stage of Pseudoterranova decipiens (Nematoda, Anisakidae). Revista de Saúde Pública, v. 31, p. 178-181, 1997.

MERCADO, R.; TORRES, P.; MUÑOZ, V.; APT, W. Human infection by Pseudoterranova decipiens (Nematoda, Anisakidae) in Chile: report of seven cases. Memórias do instituto Oswaldo Cruz, v.95, n.5, p.653-655, 2001.

MOLINA-GRACÍA, A. D.; SANZ, P. D. Anisakis simplex larva killed by hight hydrostatic pressure processing. Journal of Food Protection, v.65, n.02, p.383-388, 2002.

MOSGOVOY, A. A. Ascaridata. In:SKRJABIN; SHIKHOBALOVA; MOSGOVOY. Key to parasitic nematodes. Moscow: Akademiya Nauk SSSR Publishers, 1951. v. 2, p. 407-566.

MYERS, B. J. Research then and now on the Anisakidae nematodes. Trans American Microscopy Society, v. 95, p. 137 - 142, 1976.

NAHUM, V. J. I. Exploração e Manejo dos Recursos Pesqueiros do Litoral Amazônico: Um Desafio Para O Futuro. Cienca e Cultura, v.58, n.3, 2006.

OLIVEIRA, E. R. N.; VIEGAS, E. M. M. Qualidade do Pescado. In: RANZANI-PAIVA, M. J. T.; TAKEMOTO, R. M.; LIZAMA, M. A. P. Sanidade de Organismos Aquáticos. São Paulo: Livraria Varela. Parte VI. Cap 21. p. 415-426. 2004.

OLIVEIRA, S. A. L. Pesquisa de helmintos em musculatura e serosa Abdominal de peixes de importância comercial capturados no litoral Norte do Brasil. Dissertação de Mestrado. Universidade Federal do Pará. Pará.2005.

OVERSTREET, R. M. Poecilancistrium caryophyllum and other Trypanorhynch cestode plerocercoids from the musculature of Cynoscion nebulosus and other sciaenid fishes in the Gulf of Mexico. Journal of Parasitology, v. 63, n. 5, p. 780-789, 1977.

PALM, H. Trypanorhynch cestode of commercial fishes from northeast brazilian coastal waters. Memórias do Instituto Oswaldo Cruz, v. 92, n. 1, p. 69-79, 1997.

PAVANELLI, G. C.; EIRAS, J. C.; TAKEMOTO, R. M. Doenças de Peixe: profilaxia, diagnóstico e tratamento. Maringá: EDUEM: CNPq: Nupélia, 264p. 1998.

PEREIRA, A. D.; ATUI, M. B.; TORRES, D. M. A. G. V.; MANGINI, A. C. S.; ZAMBONI, C. Q. Incidência de parasitos da família Anisakidae em bacalhau (Gadus morhua) comercializados no Estado de São Paulo. Revista do Instituto Adolfo Lutz, v. 59, n. $1 / 2$, p. $45-49,2000$.

PINEL, C. Gastric anisakidosis due to Pseudoterranova decipiens larva. Lancet, v.347, p.1829, 1996.

PRADO, S.P.T.; CAPUANO, D.M. Relato de nematóides da família Anisakidae em bacalhau comercializado em Ribeirão Preto, São Paulo. Revista da Sociedade Brasileira de Medicina Tropical, v.39, n. 6, p. 580-581, 2006. 
REGO, A. A. Redescrição de Pterobothrium crassicolle Diesing, 1850 (Cestoda: Trypanorhyncha) e revalidação da espécie. Memórias do Instituto Oswaldo Cruz, v. 82, n. 1, p. 51-53, 1987.

REGO, A. A.; SANTOS, C. P. Helmintofauna de cavalas, Scomber japonicus Houtt, do Rio de Janeiro. Memórias do Instituto Oswaldo Cruz, v. 78, p. 443-448, 1983.

REGO, A. A.; SANTOS, J. C.; SILVA, P. P. Estudo de cestóides de peixes do Brasil. Memórias do Instituto Oswaldo Cruz, v. 72, n. 3/4, p. 187-204, 1974.

REGO, A. A.; VICENTE, J.J.; SANTOS, C.P.; WEKID, R.M. Parasitas de anchovas, Pomatomus saltatrix (L.) do Rio de Janeiro. Ciência e Cultura, v. 35, n. 9, p. 13291336, 1983.

RUSHOVICH, A. M. Omental Anisakiasis: A rare mimic of acute appendicitis. American Journal Clinical Pathologic, v. 80, p. 517-520, 1983.

SABATER, E.I.L.; SABATER, C.J.L. Riesgos para la salud asociados al parasitismo del pescado por nematodos de los géneros Anisakis y Pseudoterranova. Food Science and Technology Internacional, v. 6, n.3, p. 183-195, 2000.

SAKANARI, J. A. Intestinal Anisakiasis: A case diagnosed by morphologic and immunologic methods. American Journal Clinical Pathologic, v. 90, p. 107-113, 1988.

SÁNCHEZ-MONSALVEZ, I.; DE ARMAS-SERRA, C.; MARTÍNEZ, J.; DORADO, M.; SÁNCHEZ, A.; RODRÍGUEZ-CAABEIRO, F. A new procedure for marinating fresh anchovies and ensuring the rapid destruction of Anisakis larvae. Journal of Food Protection, v.68, n.5, p.1066-1072, 2005.

SANTOS, C. A. M. L.; ZOGBI, E. P. V. Infestation of fish in Brazil with Tetrarhynchus fragilis larvae. In: Fish Inspection and Quality Control. Roma: FAO, 1971. p. 262 264.

SANTOS, R. S., PIMENTA, F. D. A., MARTINS, M. L., TAKAHASHI, H. K., MARANGONI, N. G. Metacercárias de Diplostomum (Austrodiplostomum) compactum Lutz, 1928 (Digenea: Diplostomidae) em peixes do rio Paraná, Brasil. Prevalência, sazonalidade e intensidade de infecção. Acta Scientiarum, v. 24, n. 2, p. 475 - 480, 2002.

SANYO T. M. The fishery resourses study of the Amazon and Tocantins River mouth areas in the Federative Republic of Brazil: Japan International Final report. Cooperation Agency (JICA); Museu Paraense Emílio Goeldi (MPEG); Instituto Brasileiro do Meio Ambiente e dos Recursos Renováveis (IBAMA). 1998, 331p.

SÃO CLEMENTE, S. C. Plerocercos da Ordem Trypanorhyncha, parasitos de Corvina Micropogonias furnieri (Desmarest) no litoral do Estado do Rio de Janeiro. Atas da Sociedade de Biologia do Rio de Janeiro, n. 26, p. 29-36, 1986 . 
SÃO CLEMENTE, S. C. Prevalência e intensidade média de infecção de plerocercos de Trypanorhyncha parasitando Corvina Micropogonias furnieri (Desmarest) no litoral do Estado do Rio de Janeiro. Atas da Sociedade de Biologia do Rio de Janeiro, n.26, p. 37-40, 1986b.

SÃO CLEMENTE, S. C. Plerocercos de cestóides da ordem Trypanorhyncha em corvina Micropogonias furnieri (Desmarest) e sua importância na inspeção sanitária. Arquivos Fluminense de Medicina Veterinária, v. 2, p. 82-83, 1987.

SÃO ClEMENTE, S. C.; COELHO, M. R. T.; SERRA-FREIRE, N. M. Cestóides parasitos de Bagre Netuma barba (Lacépede, 1803) pescados no litoral do Rio de Janeiro e comercializados para consumo humano. Arquivos da Universidade Federal Rural do Rio de Janeiro, v. 14, n. 1, p. 27-34, 1991.

SÃO CLEMENTE, S. C.; MATOS, E.; UCHOA, C. M. A.; MATOS, P. Trypanorhyncha plerocerci in fish of commercial importance in Brazil. Parasitología al Dia, v. 17, p. 51-53, 1993a.

SÃO CLEMENTE, S. C. Inspeção sanitária do pescado. Higiene Alimentar, v. 7, n.28, p. 7, 1993b.

SÃO CLEMENTE, S. C.; UCHOA, C. M. A.; SERRA-FREIRE, N. M. Larvas de anisakídeos em Pagrus pagrus (L.) e seu controle através de baixas temperaturas. Revista Brasileira de Ciência Veterinária, v. 1, p. 21 - 24, 1994.

SÃO CLEMENTE, S. C.; LIMA, F. C.; UCHOA, C. M. A. Parasitos de Balistes vetula e sua importância na inspeção da pescado. Revista Brasileira de Ciência Veterinária, v. 2, n. 2, p. 39-41, 1995a.

SÃO CLEMENTE, S. C.; MARQUES, M. C.; SERRA-FREIRE, N. M.; LUCENA, F. P. Análise do parasitismo de peixe espada Trichiurus lepturus $L$. do litoral do Rio de Janeiro - Brasil. Parasitología al Dia, v. 19, n. 3-4, p. 146-149, 1995b.

SÃO CLEMENTE, S. C.; PEREIRA JÚNIOR, J.; KNOFF, M.; SILVA, C. M.; FERNANDEZ, J. G.; COUSIN, J. C. Hepatoxylon trichiuri (Holten, 1802) Dollfus, 1942 (Eucestoda: Trypanorhyncha) of Prionace glauca (Linnaeus, 1758), from the coast of state of Rio Grande do Sul, and of Coryphaena hippurus Linnaeus, 1758, from the coast of state of Rio de Janeiro, Brazil. Parasitología al Dia, v. 25, n. 3-4, 2001.

SÃO CLEMENTE, S. C.; SILVA, C. M.; GOTTSCHALK, S. Prevalência e intensidade de infecção de cestóides Trypanorhyncha em Anchovas, Pomatomus saltatrix (L.) do litoral do Rio de Janeiro, Brasil. Parasitología. al Dia, v. 21, p. 54-57, 1997.

SEAP - Secretaria Especial de Aquicultura e Pesca 2008. Disponível em: $<$ http://www.seap.pr.gov.br> Acesso em: 24 de jan. de 2010.

SEMPROR - Secretaria Municipal de Produção Rural. Prefeitura Municipal de Parauapebas.Disponívelem:<http://www.parauapebas.pa.gov.br/index.php?option=C om content\&view=article\&id=59\&/temid=70> Acesso em: 08 de dez. de 2009. 
SEPOF - Secretaria de Estado de Planejamneto, Orçamento e Finaças. Disponível em: < http://www.sepof.pa.gov.br/> Acesso em: 08 de dez. de 2009.

SILVA, C. M.; SÃO CLEMENTE, S. C. Nematóides da família Anisakidae e cestóides da ordem Trypanorhyncha em filés de dourado (Coryphaena hippurus) e ariocó (Lutjanus synagris) e sua importância na inspeção de pescado. Higiene Alimentar, v. 15, n. 80/81, p. $75-79$, jan. - fev, 2001.

SMITH, J. W.; WOOTTEN, R. Anisakis and Anisakiasis. Advances in Parasitology, v. 16, p. 93-163, 1978.

SNATURAL - Peixes, doenças e parasitoses. Disponível em: < http://www.snatural.com.br/> Acesso em: 08 de dez. de 2009.

SOUZA, J. E., E. N. FRAGOSO-MOURA, N. FENERICH-VERANI, O. ROCHA; J. R. VERANI. Population structure and reproductive biology of Cichla kelberi (Perciformes, Cichlidae) in Lobo Reservoir, Brazil. Neotropical Ichthyology, v.6, n.2, p. 201-210, 2008.

SUGIMACHI, K. Acute gastric anisakiasis: Analysis of 178 cases. Journal American Medicine, v. 253, p. 1012-1013, 1985.

TAKEMOTO, R.M.; LIZAMA, M.A.P.; GUIDELLI, G.M.; PAVANELLI, G.C. Parasitos de Peixes de Águas Continentais. In: RANZANI-PAIVA, M. J. T.; TAKEMOTO, R. M.; LIZAMA, M. A. P. Sanidade de Organismos Aquáticos. São Paulo: Livraria Varela. Parte II. Cap 08. p. 179-198. 2004.

TAVARES L.E.R; LUQUE, J.L. 2006. Sistemática, biologia e importância em saúde coletiva de larvas de Anisakidae (Nematoda: Ascaridoidea) parasitas de peixes ósseos marinhos do Estado do Rio de Janeiro, Brasil. In: A. T. SILVA-SOUZA (Ed.), Sanidade de Organismos Aquáticos no Brasil. Maringá: Abrapoa, p. 297-328.

TEIXEIRA FILHO, A.R. Piscicultura ao alcance de todos. Editora Nobel: São Paulo, 1991, 190p.

THIEL, P.H.V.; KUIPERS, F.C.; ROSKAM, R.T.H. A nematode parasitic to herring, causing acute abdominal syndromes in man. Tropical Geographic Medicine, v. 2, p. 97-113, 1960.

TIMI, J.T.; SARDELLA, N.H.; NAVONE, G.T. Parasitic nematodes of Engraulis anchoita Hubbs et Marini, 1935 (Pisces, Engraulidae) off the Argentine and Uruguayan coasts, South West Atlantic. Acta Parasitology, v.46, p.186-193, 2001.

TORRES, M., CANALES, M., CONCHA, M., COFRE, X., TELLES, P. Un caso de anisakiosis en un adulto. Parasitoogía al Día, v. 24, p. 3-4, jul, 2000.

UBEIRA, F.M., VALINÑAS, B. LORENZO, S., IGLESIAS, R., FIGUEIRAS, A., GARCÍA-VILLAESCUSA, R. Anisaquiosis y Alergia:Estudio seroepidemiológico en La Comunidad Autónoma Gallega. In: .Documentos Técnicos de Salud Pública. n. 24, Xunta de Galícia: Consellería de Sanidade e Servicios Sociais, 2000, $102 \mathrm{p}$. 
UKUMURA, M. P. M.; PADOVANI, R. E. S.; SÃO CLEMENTE, S. C. Pesquisa de nematódeos e trematódeos em sushi e sashimi comercializados na grande São Paulo - resumo. Higiene Alimentar. São Paulo: v. 15, n. 80/81, p. 111, 2001.

UKUMURA, M. P. M.; PÉREZ, A. C. A.; ESPÍNDOLA FILHO, A. Principais zoonoses parasitárias transmitidas por pescado - revisão. Revista de Educação Continuada do CRMV-SP, v. 2, n. 2, p. 66-80, 1999.

VALDISERRI, R.O. Intestinal anisakiasis: Report of a case and recovery of larvae from market fish. American Journal of Clinical Pathologic, v. 76, p. 329-333, 1981.

VALLS, A.; PASCUAL, C.Y.; MARTÍN ESTEBAN, M. Anisakis allergy: an update. Revue française d'allergologie et d'immunologie Clinique, v. 45, p.108-113, 2005.

VÁZQUEZ-LÓPEZ C, ARMAS-SERRA C, RODRÍGUEZ-CAABEIRO F. Gymnorhynchus gigas: taxonomía, morfología, biología y aspectos sanitarios. Analecta Veterinaria, v. 21, n.2, p. 38-49, 2001.

VERA, J. J. A. Anisakiasis como causa de apendicites aguda y cuadro reumatológico: primer caso em la literatura médica. Revista Española de Enfermidade Digestiva, v. 79, p. 355-358, 1991.

VICENTE, J. J.; RODRIGUES, H. O.; GOMES, D. C. Nematóides do Brasil. 1a parte: nematóides de peixes. Atas da sociedade de biologia, v. 25, p. 1-79, 1985.

WHARTON, D.A.; AALDERS, O.. The response of Anisakis larvae to freezing. Journal of helminthology, v. 76, p.363-368, 2002.

YAMAGUTI, S. Studies on the helminth fauna of Japan. Part 4. Cestodes of fishes. Japanes Journal of Zoology, v.6, n.1, p.1-112, 1934.

YOKOGAWA, M.; YOSHIMURA, H. Anisakis - like larvae causing eosinophilic granulomata in the stomach of man. American Journal Tropical Medicine, v. 14, p. 770-773, 1965.

YOKOGAWA, M.; YOSHIMURA, H. Clinicopathologic studies on larval anisakiasis in Japan. American Journal Tropical Medicine, v. 16, p. 723-728, 1967.

YORKE, W.; MAPLESTONE, P. A. The nematode parasites of vertebrates. London: J. e A. Churchill, 1926. 536 p.

ZUANON, J. A.S. Aspectos da biologia, ecologia e pesca de grandes bagres (Pisces: Siluriformes, Siluroide) na área da ilha de Marchantaria - rio solimões, Am. Tese de Mestrado, INPA/FUA, Manaus. 1990.

ZULOAGA, J.; ARIAS, J.; BALIBREA, J.L. Anisakiasis digestive. Aspectos de interés para el cirujano. Cirurgía española, v.75, n.1, p. 9-13, 2004. 